OPEN ACCESS

Edited by: Heiko Mühl,

Goethe University Frankfurt, Germany

Reviewed by:

Martin Rottenberg,

Karolinska Institutet, Sweden

James M. Murphy,

Walter and Eliza Hall Institute of

Medical Research, Australia

${ }^{*}$ Correspondence:

Alexander Dalpke

alexander.dalpke@med.

uni-heidelberg.de

†Jana Zimmer and Michael Weitnauer contributed equally to this work.

Specialty section: This article was submitted to Inflammation,

a section of the journal

Frontiers in Immunology

Received: 06 September 2016 Accepted: 04 November 2016 Published: 18 November 2016

Citation:

Zimmer J, Weitnauer M, Boutin S, Küblbeck G, Thiele S, Walker P, Lasitschka F, Lunding L, Orinska Z, Vock C, Arnold B, Wegmann M and Dalpke A (2016) Nuclear Localization

of Suppressor of Cytokine

Signaling-1 Regulates Local Immunity in the Lung.

Front. Immunol. 7:514. doi: 10.3389/fimmu.2016.00514

\section{Nuclear Localization of Suppressor of Cytokine Signaling-1 Regulates Local Immunity in the Lung}

\author{
Jana Zimmer ${ }^{1 \dagger}$, Michael Weitnauer ${ }^{1 \dagger}$, Sébastien Boutin ${ }^{1,2,3}$, Günter Küblbeck ${ }^{4}$, \\ Sabrina Thiele ${ }^{1}$, Patrick Walker ${ }^{1}$, Felix Lasitschka ${ }^{5}$, Lars Lunding ${ }^{3,6,7}$, Zane Orinska ${ }^{3,7,8}$, \\ Christina Vock ${ }^{3,7,8}$, Bernd Arnold ${ }^{4}$, Michael Wegmann ${ }^{3,6,7}$ and Alexander Dalpke ${ }^{1,2,3 *}$ \\ ${ }^{1}$ Department of Infectious Diseases, Medical Microbiology and Hygiene, University Hospital Heidelberg, Heidelberg, \\ Germany, ${ }^{2}$ Translational Lung Research Center Heidelberg (TLRC), Heidelberg, Germany, ${ }^{3}$ German Center for Lung \\ Research (DZL), Germany, ${ }^{4}$ German Cancer Research Center (DKFZ), Heidelberg, Germany, ${ }^{5}$ Institute of Pathology, \\ University Hospital Heidelberg, Heidelberg, Germany, ${ }^{6}$ Division of Asthma Mouse Model, Research Center Borstel, Borstel, \\ Germany, ${ }^{7}$ Airway Research Center North, Borstel, Germany, ${ }^{8}$ Division of Experimental Pneumology, Prority Area Asthma \& \\ Allergy, Research Center Borstel, Borstel, Germany
}

Suppressor of cytokine signaling 1 (SOCS1) is a negative feedback inhibitor of cytoplasmic Janus kinase and signal transducer and activator of transcription (STAT) signaling. SOCS1 also contains a nuclear localization sequence (NLS), yet, the in vivo importance of nuclear translocation is unknown. We generated transgenic mice containing mutated Socs $1 \Delta N L S$ that fails to translocate in the cell nucleus ( $M G L^{\text {tg }}$ mice). Whereas mice fully deficient for SOCS1 die within the first 3 weeks due to excessive interferon signaling and multiorgan inflammation, mice expressing only non-nuclear Socs $1 \Delta N L S$ (Socs $1^{-l-M G L^{t g}}$ mice) were rescued from early lethality. Canonical interferon

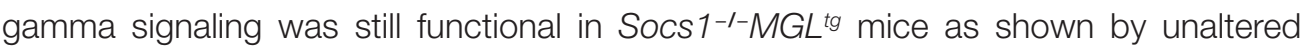
tyrosine phosphorylation of STAT1 and whole genome expression analysis. However, a subset of NFKB inducible genes was dysregulated. Socs $1^{-I-} M G L^{\text {tg }}$ mice spontaneously developed low-grade inflammation in the lung and had elevated Th2-type cytokines. Upon ovalbumin sensitization and challenge, airway eosinophilia was increased in Socs $1^{-1-} M G L^{\text {tg }}$ mice. Decreased transepithelial electrical resistance in trachea epithelial cells from Socs $1^{-1-M G L}{ }^{\text {tg }}$ mice suggests disrupted epithelial cell barrier. The results indicate that nuclear SOCS1 is a regulator of local immunity in the lung and unravel a so far unrecognized function for SOCS1 in the cell nucleus.

Keywords: rodent, inflammation, signal transduction, transgenic mice, lung, socs1

\section{INTRODUCTION}

The suppressor of cytokine signaling (SOCS) family is important for negative feedback inhibition of Janus kinases (JAKs) and signal transducer and activator of transcription (STAT) signaling. All eight members, namely SOCS1-7 and CIS, share key structural elements such as the central cytokine-inducible Src-homology $2(\mathrm{SH} 2)$ domain and the shared C-terminal SOCS-box $(1,2)$. Both SOCS1 and SOCS3 additionally contain a kinase inhibitory region 
(KIR) by which they can act as a pseudosubstrate for JAKs (3). SOCS1 was first described in 1997 as a negative feedback inhibitor of cytoplasmic JAK/STAT signaling (4-6). By the means of the extended SH2 subdomain (eSS) and the KIR, SOCS1 directly binds to JAK2, thereby inhibiting its catalytic activity (3). SOCS1 has further been shown to occupy binding sites for STATs by interacting with interferon receptor domains $(7,8)$. Finally, the SOCS box in SOCS1 mediates interactions with elongins $\mathrm{B}$ and $\mathrm{C}$ and acts as an $\mathrm{E} 3$ ubiquitin ligase that targets JAKs or cytokine receptor complexes for proteasomal degradation $(9,10)$. In addition to JAK/STAT signaling, SOCS1 has been shown to act as a cross talk inhibitor for TLR signaling pathways $(11,12)$. Besides indirect paracrine inhibition of TLR signaling by IFN $\beta$ (13), SOCS1 additionally contributes to direct negative regulation by interacting with components of the TLR signaling pathway $(12,14)$.

Canonical IFN $\gamma$ signaling functions by binding to the IFN $\gamma$ receptor complex, activating Janus kinases (JAK1/2), and subsequent phosphorylation of STAT1 that dimerizes and translocates into the nucleus. Once in the nucleus, activated pY-STAT1 binds to gamma-activated sequence (GAS) elements within the promoters of IFN $\gamma$-responsive genes (ISGs) - mostly, "canonical" antiviral genes $(15,16)$. While pY-STAT1 is thought to be pivotal for the IFN $\gamma$ response, a number of studies have shown that pY-STAT1-independent pathways also exist (17-19). There is emerging evidence that STAT-independent pathways play important roles in mediating signals for the generation of IFN $\gamma$ responses such as the mitogen-activated protein kinase (MAPK) or PI3K/AKT pathway (20). It has been previously shown that IFNAR1, TYK2, and STAT1 may translocate into the nucleus $(21,22)$. The presence of unphosphorylated STAT1 in the cell nucleus has been shown to increase expression of only a subset of "non-canonical" IFN $\gamma$-induced genes that are pY-STAT1independent (23).

Socs $1^{-1-}$ mice die within $2-3$ weeks due to unlimited IFN $\gamma$ signaling leading to multiorgan inflammation (24-26). Deletion of the SOCS box of SOCS1 delays the onset of the disease (27). Alleviation from the lethal phenotype of Socs $1^{-/-}$mice can be achieved by backcrossing to IFN $\gamma^{-/-}$mice; however, these mice develop polycystic kidneys as well as chronic inflammation (28). Moreover, Socs $1^{-/-}$mice can be rescued by backcrossing to either $\mathrm{STAT4}^{-/-}$, or STAT6 ${ }^{-/-}$mice $(25,29)$, or $\mathrm{Rag}^{-/-}$mice $(30)$, revealing an important role of SOCS1 in T cells. Since Socs $1^{-/-}$mice have defective thymocyte development, and overexpression of Socs 1 impairs pre-TCR-induced thymocyte proliferation, inhibition of cytokine signaling has important influence on $\mathrm{T}$ cell differentiation $(31,32)$.

In 2008, a nuclear localization sequence (NLS) has been identified in SOCS1 located between the central SH2 domain and the SOCS box (amino acids 159-173). The NLS resulted in translocation of the protein into the cell nucleus $(33,34)$. Substitution of this sequence with the respective region of SOCS3 showed loss of nuclear localization, whereas fusion of the SOCS1-NLS to the cytoplasmic SOCS family member CIS induced nuclear localization (33). It has been shown that SOCS1 directly interacts with the tumor suppressor p53 leading to activation of p53 via phosphorylation (35). Moreover,
SOCS1 induces proteasomal degradation of $\operatorname{NF\kappa B}(36,37)$ and, in particular, it interacts with the NFKB subunit p65 in the cell nucleus, thereby limiting induction of a subset of NFKB dependent genes (38).

However, the function of SOCS1 in the cell nucleus in vivo remains elusive. Therefore, we generated a transgenic mouse that only expresses a non-nuclear mutant SOCS1. Mice with transgenic expression of a bacterial artificial chromosome (BAC) containing a mutated Socs1 locus with non-nuclear Socs1 1 NLS, eGFP, and LuciferaseCBG99 (MGL) were generated and backcrossed to Socs $1^{-/-}$mice. Socs $1^{-/} M G L^{\text {tg }}$ mice survived the early lethal phenotype of Socs $1^{-/-}$mice, showed unaltered canonical IFN $\gamma$-signaling, yet, displayed signs of low-grade airway inflammation and Th2 deviation. Decreased transepithelial electrical resistance (TER) in trachea epithelial cells from Socs $1^{-/-} M G L^{\text {tg }}$ mice suggests disrupted epithelial integrity. Socs $1^{-/-} M G L^{\text {tg }}$ mice present a valuable tool to study the nuclear function of SOCS1 in vivo and allow investigating local immune regulation in the lung by nuclear SOCS1.

\section{MATERIALS AND METHODS}

\section{Mice}

C57BL/6 mice were purchased from Charles River Laboratories. Breeding occurred under specific pathogen-free conditions in the animal facility (IBF, Heidelberg, Germany). Socs $1^{+/-}$mice (C57/Bl6.129Sv-Socs1tmWsa/Uhg) were first described by Starr et al. (26). MGL-transgenic mice were generated by pronucleus injection using a BAC containing a part of chromosome \#16 (10.78-10.80 Mb) including a mutated Socs1 locus with non-nuclear Socs1 $\triangle N L S$, eGFP (codon optimized for mouse and human), and LuciferaseCBG99 (Click Beetle Green from Pyrophorus plagiophalam), termed MGL (RP23-360O7). Pronucleus injection resulted in 12 transgenic founder mice, C57Bl6-tg(Socs1-MGL)Uhg. This work was done by Prof. Dr. Bernd Arnold and Günter Küblbeck (DKFZ, Heidelberg, Germany) in cooperation with Frank Zimmermann (IBF) and Patrick Walker. Mice are genotyped at an age of 2 weeks using PCR detecting Socs 1 wild-type (wt), Socs1 knockout, Socs1 MGL, and $\beta 2$ microglobulin $(\beta 2 M)$ (primer sequences, see Table S1 in Supplementary Material). Breeding, sacrificing, and dissection were approved and experiments properly recorded and reported to the regional commission in Karlsruhe (permit number 35-9185.81/G-54/14).

\section{Reagents}

RPMI 1640 was purchased from Biochrom (Berlin, Germany). FCS was from Life Technologies (Carlsbad, CA, USA) and Penicillin and streptomycin were from PAA Laboratories (Pasching, Austria). PBS was obtained from PAN-Biotech (Aidenbach, Germany). IFN $\gamma$ was purchased from Peprotech (\#315-05, Hamburg, Germany), polyinosinic-polycytidylic acid (pI:C) from InvivoGen (Toulouse, France) and phosphorothioatemodified CpG-oligonucleotide 1668 from TIB Molbiol (Berlin, Germany). LPS from Salmonella minnesota was kindly provided by U. Seydel (Division of Biophysics, Research Center Borstel, Borstel, Germany). 


\section{Cell Culture, Transfection, and Stimulation}

RAW264.7 or NIH cells were cultured at $37^{\circ} \mathrm{C}$ and $5 \% \mathrm{CO}_{2}$ in RPMI or DMEM, respectively. Cell culture medium was further supplemented with $10 \%(\mathrm{v} / \mathrm{v})$ heat-inactivated fetal calf serum (FCS), penicillin (50 units $/ \mathrm{ml}$ ), and streptomycin $(50 \mu \mathrm{g} / \mathrm{ml})$ (P/S). For transfection of RAW264.7 or NIH cells, the transfection reagents JetPRIME (Polyplus, Illkirch, France) or PeqFect (peqlab Biotechnology, Erlangen, Germany) were used and transfection was performed according to the manufacturer's protocol. Bone marrow-derived macrophages (BMM) were isolated from mice as described previously (39). Briefly, bone marrow cells were seeded into a $14.5 \mathrm{~cm}$ dish in DMEM plus FCS and P/S and differentiated using 30\% (v/v) L929 supernatant (containing M-CSF) for 7 days. For cycloheximide $(\mathrm{CHX})$ chase, $1 \times 10^{6} \mathrm{BMMs}$ were stimulated with IFN $\gamma$ for $6 \mathrm{~h}$ and chased with $100 \mu \mathrm{g} / \mathrm{ml} \mathrm{CHX} \mathrm{(Merck}$ Millipore, MA, USA).

\section{Immunofluorescence Microscopy}

$\mathrm{NIH}$ cells were grown on $\mu$-slides (8-well, ibidi, Martinsried, Germany) and transfected with $0.5 \mu \mathrm{g}$ GFP-Socs1 or GFPSocs $1 \Delta N L S$ using PeqFect (peqlab Biotechnology, Erlangen, Germany). Where indicated, cells were stained with Hoechst $(1 \mu \mathrm{g} / \mathrm{ml})$ for $2 \mathrm{~min}$ or with CellMask ${ }^{\mathrm{TM}}$ Plasma Membrane Stain (ThermoFisher Scientific, Waltham, MA, USA, 1:1000) for $10 \mathrm{~min}$ at room temperature. Coverslips were mounted and analyzed by microscopy using a Leica TCS SP5 confocal microscope (Leica Microsystems, Wetzlar, Germany) equipped with a 488- and 561-nm laser, spectrophotometer prism, tunable detectors, and a HCX PL APO $63 \times / 1.4$ oil objective. All channels were recorded in a sequential order to avoid emission cross talk. A $z$-stack was recorded and presented as an overlay using ImageJ (National Institutes of Health). For quantification of the fluorescence, a region of interest (ROI) was set around the nucleus or the cytoplasm of a cell and intensity of the fluorescence was examined in a $z$-stack using ImageJ.

\section{Quantitative RT-PCR}

Total RNA from $2.5 \times 10^{5}$ cells was isolated using the peqGOLD RNA Kit (peqlab Biotechnology, Erlangen, Germany) according to the manufacturer's protocol. After reverse transcription into cDNA using the High Capacity cDNA Reverse Transcription Kit (Applied Biosystems, Foster City, CA, USA), $5 \mu \mathrm{l}$ cDNA (diluted 1:10) was used as template in a quantitative real-time PCR using SYBR Green FAST Mix (Applied Biosystems). Amplification and measurement was done in a StepOne Plus RT-PCR cycler (Applied Biosystems) in a 96-well format. Specificity of qPCR was controlled by non-template as well as no-RT samples and analysis of melting curves. Results are shown relative to the housekeeping gene $\beta$-Actin (ActB). Primer sequences are given in Table S1 in Supplementary Material. qPCR for Socs $1 w t$ was performed with TaqMan Fast Universal PCR Master Mix (Applied Biosystems) in combination with a forward primer (P1) binding in the $\mathrm{SH} 2$ domain and a reverse primer (P2) binding in the SOCS box and a FAM-labeled probe binding in the NLS of Socs1. SYBR green dye in combination with P1 and a reverse primer (P3) within the modified NLS region were used for the detection of Socs $1 \Delta N L S$. For detection of total Socs 1 (both
Socs 1 and Socs $1 \Delta N L S)$, the primers P1 and P2 were used. This qPCR strategy allows for specific detection of Socs1, Socs $1 \Delta N L S$, or total Socs1. The amplification efficiencies for both Socs $1 w t$ (1.68) and Socs1 $\Delta N L S$ (1.88) were adjusted for differences.

\section{Western Blotting}

Also, $1 \times 10^{6}$ BMMs or RAW264.7 cells were stimulated as indicated, subsequently washed with PBS, and lysed in Laemmli buffer [ 400 mM Tris-HCl, pH 6.8, 20\% (v/v) $\beta$-mercaptoethanol, $40 \%(\mathrm{v} / \mathrm{v})$ glycerol, $8 \%(\mathrm{w} / \mathrm{v})$ SDS, and $0.4 \%(\mathrm{v} / \mathrm{v})$ bromophenol blue]. After incubation for $10 \mathrm{~min}$ at $98^{\circ} \mathrm{C}$, equal amounts of lysates were fractionated by $10 \%$ polyacrylamide gel (SDSPAGE) and electrotransferred to Nitrocellulose membranes by a semidry blotting procedure [buffer: $25 \mathrm{mM}$ Tris, $192 \mathrm{mM}$ Glycin, $10 \%(\mathrm{v} / \mathrm{v})$ methanol; $2.5 \mathrm{~mA} / \mathrm{cm}^{2}$ for $1 \mathrm{~h} 15 \mathrm{~min}$ ]. Blocking of unspecific binding was performed using 5\% BSA solution in $1 \times$ TBST [ $1 \times$ TBS, $0.05 \%(v / v)$ Tween-20] for at least $1 \mathrm{~h}$. Membranes were stained with antibodies against pY-STAT1 (Tyr701, \#9167), STAT1 (\#9172), IкB $\alpha$ (\#9242), $\beta$-Actin (\#4970) (Cell Signaling, Leiden, Netherlands; 1:1000), or hybridoma cell supernatant for SOCS1 detection (hybridoma cells newly generated by immunizing mice against the peptide RRITRASALLDA, Abmart, Shanghai, 1:20 dilution) overnight at $4^{\circ} \mathrm{C}$. After three 10 min washing steps in $1 \times$ TBST at room temperature, blots were incubated with secondary antibodies for $1 \mathrm{~h}$ at RT [HRP-linked anti-mouse or anti-rabbit (Cell Signaling, Leiden, Netherlands)], followed by additional three $10 \mathrm{~min}$ washing steps in $1 \times$ TBST at room temperature. Proteins were detected using an enhanced chemiluminescence system (Western lightning $^{\mathrm{TM}}$ plus ECL, Perkin-Elmer, Rodgau, Germany). Gels were imaged digitally, and contrast adjustments were applied to all parts of a figure. The prestained molecular weight marker was imaged separately (using transmitted light) and aligned to the digital images of the blots. The ladder is represented on the blots as black bars. Where indicated, membranes were stripped and reprobed. Densitometry was performed using ImageJ software (National Institutes of Health).

\section{Immunohistochemistry}

For immunohistochemistry, lungs were fixed overnight in $4 \%$ (v/v) formalin and embedded in paraffin. Two micrometers lung sections were cut and stained for SOCS1 using the DAB staining method (Abcam, Cambridge, UK or Dako, Glostrup, Denmark). After deparaffination, demasking of the antibody followed using either citrate buffer [ $10 \mathrm{mM}$ sodium citrate, $0.05 \%(\mathrm{v} / \mathrm{v})$ Tween 20, pH 6.0] or EDTA buffer [1 mM EDTA, pH 8.0] for 15-45 min in a steamer. Incubation with peroxidase-blocking solution and protein blocking solution was followed by incubation with the anti-SOCS1 antibody at varying concentrations (1:50-1:2000) at $4^{\circ} \mathrm{C}$ overnight. The commercially available antibodies from cell signaling (\#3950, Leiden, Netherlands), Abcam (\#ab-9870, Cambridge, UK), and Santa Cruz (\#sc-9021, Santa Cruz Biotechnology, Heidelberg, Germany) were tested as well as hybridoma cell supernatant (newly generated by immunizing mice against the peptide RRITRASALLDA, Abmart, Shanghai) and a newly generated antibody against recombinant SOCS1 (generated against recombinant SOCS1 by immunizing 
mice at Charles River, Chatillon-sur-Chalaronne, Ecully, France). On the next day, incubation with serum corresponding to the species of the secondary antibody followed. Incubation with the secondary antibody (goat anti-rabbit antibody or goat anti-mouse antibody) was performed for $30 \mathrm{~min}$. After washing, sections were incubated with the chromogen (liquid diaminobenzidine and peroxide buffer) until a reaction was visible. Slides were counterstained with hematoxylin to provide nuclear and morphologic detail and mounted. Lung sections of Socs $1^{-/-}$mice were used as a negative control.

\section{Flow Cytometry}

The $2.5 \times 10^{5}$ BMMs were harvested in PBS plus $2 \%$ (v/v) FCS and analyzed by FACSCanto flowcytometer gating on GFP positive cells (BD Bioscience, Heidelberg. Germany).

\section{Luciferase Activity Assay}

The $2.5 \times 10^{5}$ BMMs were lysed in Luciferase lysis buffer [ $1 \%(\mathrm{v} / \mathrm{v})$ Triton X-100, 25 mM Glycyl-Glycine (pH 7.8), 15 mM MgSO4, $4 \mathrm{mM}$ EGTA, and $1 \mathrm{mM}$ DTT]. After injection of Luciferase assay buffer [25 mM K${ }_{3} \mathrm{PO}_{4}\left(\mathrm{pH} 7.8\right.$ ), $0.225 \mathrm{mM} \mathrm{MgSO}_{4}, 0.08 \mathrm{mM}$ EGTA, $2 \mathrm{mM}$ ATP, $1 \mathrm{mM}$ DTT, and $0.125 \mathrm{mM}$ glycylglycine] to each well, activities in the lysates were measured using a luminometer (LUMIstar OPTIMA system, BMG LABTECH). Luminescent units are presented per microgram as determined by calorimetric Bradford assay using the Rotiquant reagent (Roth $\mathrm{GmbH}$, Karlsruhe, Germany).

\section{Whole-Genome Expression Analysis}

Total RNA from $2.5 \times 10^{5}$ BMMs was isolated as described above. The quality of total RNA was checked by gel analysis using the total RNA Nano chip assay on an Agilent 2100 Bioanalyzer (Agilent Technologies GmbH, Berlin, Germany). Only samples with RNA index values greater than 8.5 were selected for expression profiling. RNA concentrations were determined using the NanoDrop spectrophotometer (NanoDrop Technologies, Wilmington, DE, USA). The laboratory work was done in the Genomics and Proteomics Core Facility at the German Cancer Research Center, Heidelberg, Germany (DKFZ). Biotin-labeled cRNA samples for hybridization on Illumina Mouse Sentrix-8 BeadChip arrays (Illumina, Inc.) were prepared according to Illumina's recommended sample labeling procedure based on the modified Eberwine protocol (40). In brief, $300 \mathrm{ng}$ total RNA was used for complementary DNA (cDNA) synthesis, followed by an amplification/labeling step (in vitro transcription) to synthesize biotin-labeled cRNA according to the Illumina ${ }^{\circledR}$ Total Prep ${ }^{\mathrm{TM}}$ RNA Amplification Kit (Life Technologies). Biotin-16-UTP was purchased from Roche Applied Science, Penzberg, Germany. The cRNA was column purified according to TotalPrep RNA Amplification Kit, and eluted in $60 \mu \mathrm{l}$ of water. Quality of cRNA was controlled using the RNA Nano Chip Assay on an Agilent 2100 Bioanalyzer and spectrophotometrically quantified (NanoDrop). Hybridization was performed at $58^{\circ} \mathrm{C}$, in GEX-HCB buffer (Illumina, Inc.) at a concentration of $100 \mathrm{ng} \mathrm{cRNA} / \mu \mathrm{l}$, unsealed in a wet chamber for $20 \mathrm{~h}$. Spike-in controls for low, medium, and highly abundant RNAs were added, as well as mismatch control and biotinylation control oligonucleotides. Microarrays were washed once in high temp wash buffer (Illumina, Inc.) at $55^{\circ} \mathrm{C}$ and then twice in E1BC buffer (Illumina, Inc.) at room temperature for 5 min (in between washed with ethanol at room temperature). After blocking for $5 \mathrm{~min}$ in $4 \mathrm{ml}$ of $1 \%$ (wt/vol) Blocker Casein in phosphate buffered saline Hammarsten grade (Pierce Biotechnology, Inc., Rockford, IL, USA), array signals were developed by a $10 \mathrm{~min}$ incubation in $2 \mathrm{ml}$ of $1 \mu \mathrm{g} / \mathrm{ml} \mathrm{Cy3}$-streptavidin (Amersham Biosciences, Buckinghamshire, UK) solution and 1\% blocking solution. After a final wash in E1BC, the arrays were dried and scanned. Microarray scanning was done using an iScan array scanner. Data extraction was done for all beads individually, and outliers were removed when $>2.5$ median absolute deviation (MAD). All remaining data points were used for the calculation of the mean average signal for a given probe, and SD for each probe was calculated (ArrayExpress accession E-MTAB-4938). Data was processed using $\mathrm{R}$, including $\log 2$ transformation of the data, significance $(p \leq 0.05)$, and fold change (log $2 \leq-1$ or $\geq 1$ ) filtered. Data were normalized to remove systematic variation and background subtraction. Pathway annotation was performed using the Protein Analysis through Evolutionary Relationships (PANTHER) classification system and transcription factor binding sites (TFBS) among the differentially regulated genes were analyzed using the overrepresentation analysis tool oPOSSUM.

\section{Enzyme-Linked Immunosorbent Assay}

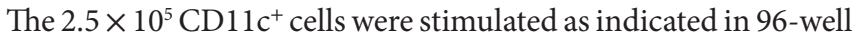
plates in $200 \mu \mathrm{l}$ RPMI supplemented with $10 \%$ (v/v) FCS and $\mathrm{P} / \mathrm{S}$. Supernatants were harvested and analyzed for cytokines by commercially available enzyme-linked immunosorbent assay (ELISA) kits for TNF $\alpha$ and IL-12p40 (BD Biosciences, Heidelberg, Germany). Cytokines were detected by measuring the absorbance at $490 \mathrm{~nm}$ with a $650 \mathrm{~nm}$ reference in a photometer (Sunrise reader, Tecan, Salzburg, Austria). Cytokine concentrations were calculated according to a standard dilution of the respective recombinant cytokines using Magellan V 5.0 software (Tecan, Salzburg, Austria).

\section{OVA Sensitization and Challenge}

Mice were sensitized to ovalbumin (OVA) by three i.p. injections of $10 \mu \mathrm{g}$ OVA (OVA grade VI; Sigma-Aldrich, Deisenhofen, Germany) adsorbed to $150 \mu$ g aluminum hydroxide (Imject Alum; Thermo, Rockford, IL, USA) on days 1, 14, and 21. Mice were exposed three times to an OVA (OVA grade V; Sigma-Aldrich) aerosol [1\% (w/v) in PBS] on days 26, 27, and 28 to induce acute allergic airway inflammation (41). Sham sensitization and challenges were carried out using sterile PBS. Mice were sacrificed on day 29 by cervical dislocation under deep anesthesia. Eight animals per group were used, if not stated otherwise. Experiments were done at the Research Center Borstel under approval of the animal ethics committee from the Department of State, Kiel, Germany [permit no. V244-7224.121.3 (108-9/14)].

\section{Intratracheal IL-13 Instillation}

Mice were anesthetized with isofluorane for $30 \mathrm{~s}$ and allowed to hang vertically with their mouths open, supported by a taut 
string placed under their canine teeth. Their tongues were gently withdrawn with a blunt forceps to keep them from swallowing. Twenty microliters of PBS with or without $5 \mu$ g IL-13 (\#210-13, Peprotech, Hamburg, Germany) was applied onto the base of their tongues. When the mice had aspirated the applied solution, they were put on their site until they woke up. This intratracheal instillation was performed on days 1, 2, and 3. Mice were analyzed $24 \mathrm{~h}$ after the last treatment (permit no. 35-9185.81/G-35/16).

\section{Bronchoalveolar Lavage}

Lungs were rinsed with $1 \mathrm{ml}$ fresh, ice-cold PBS containing protease inhibitor (Roche, Basel, Switzerland) via a tracheal canula, and obtained cells were counted using a Neubauer chamber. Cytospins were prepared for each sample by centrifugation of $50 \mu \mathrm{l}$ BAL fluid plus $150 \mu \mathrm{l}$ of sterile PBS and subsequently stained with Diff-Quik (Medion Diagnostics, Duedingen, Switzerland). Cells were microscopically differentiated and classified as macrophages, neutrophils, eosinophils, or lymphocytes, using standard morphologic criteria (42).

\section{Cytokine and IgE Measurement}

Levels of IL 4, IL-5, and IL-13 in serum were measured using an enhanced sensitivity cytometric bead array (CBA, Flex Set Kits; BD Biosciences, Franklin Lakes, NJ, USA), according to the manufacturer's guidelines. IgE in serum was measured by ELISA. Briefly, 96-well high-binding ELISA plates (Greiner, Sigma-Aldrich, Deisenhofen, Germany) were coated with monoclonal anti-IgE antibodies (clone R35-72, BD Biosciences, Heidelberg, Germany) overnight. Serum samples were diluted in $1 \%(\mathrm{w} / \mathrm{v}) \mathrm{BSA}$ in PBS/0.05\% (v/v) Tween 20 and incubated overnight at $4^{\circ} \mathrm{C}$. Afterward, plates were incubated with antiIgE conjugated with HRP (clone 23G3, Southern Biotech, Birmingham, AL, USA) for $3 \mathrm{~h}$ at room temperature. For the colorimetric detection, TMB (Sigma) was used as a substrate. Absorbance was measured at $450 \mathrm{~nm}$ in ELISA reader (Infinite M200, Tecan) and IgE concentrations calculated according to standard curve.

\section{Primary Murine Tracheal Epithelial Cell Culture}

The procedure used for isolation of murine tracheal epithelial cells was adapted from Davidson et al. (43). In brief, mice were killed by $\mathrm{CO}_{2}$ inhalation. Tracheas were removed, cut lengthways, washed in PBS, and transferred to collection media [1:1 mixture of DMEM and Ham's F12 with $1 \%(\mathrm{v} / \mathrm{v})$ penicillinstreptomycin]. Tracheas were then incubated at $4^{\circ} \mathrm{C}$ overnight in dissociation media [44 mM NaHCO $3,54 \mathrm{mM} \mathrm{KCL}, 110 \mathrm{mM}$ $\mathrm{NaCl}, 0.9 \mathrm{mM} \mathrm{NaH} \mathrm{PO}_{4}, 0.25 \mu \mathrm{M} \mathrm{FeN}_{3} \mathrm{O}_{9}, 1 \mu \mathrm{M}$ sodium pyruvate, $\mathrm{pH} 7.5$, and supplemented with $1 \%(\mathrm{v} / \mathrm{v})$ penicillinstreptomycin, $0.1 \mathrm{mg} / \mathrm{ml}$ DNaseI (\#11284932001, Roche, Basel, Switzerland), and $1.4 \mathrm{mg} / \mathrm{ml}$ PronaseE (\#P5147, Sigma, MO, USA)]. Enzymatic digestion was stopped by adding 20\% FCS to the dissociation media. Epithelial cells were dissociated by gentle agitation followed by physical removal of the tracheas. Cells were then centrifuged at $1000 \times g$ for $10 \mathrm{~min}$ at RT. Cell pellets were resuspended in culture medium [1:1 mixture of DMEM and Ham's F12 with 1\% penicillin-streptomycin, 5\% FCS, and
120 U/1 insulin (\#12585014, ThermoFisher Scientific, Waltham, MA, USA)], and seeded in a $10 \mathrm{~cm}$ cell-culture dish for $2 \mathrm{~h}$ at $37^{\circ} \mathrm{C}$. The supernatant was carefully taken off and centrifuged at $1000 \times g$ for $10 \mathrm{~min}$ at RT. Cell pellets from two tracheas were resuspended in $200 \mu \mathrm{l}$ culture medium and seeded in the inner well of a transwell (\#CLS3470-48EA, Corning ${ }^{\circledR}$ Costar $^{\circledR}$, Sigma, MO, USA) coated with human placenta collagen-IV (\#C7521, Sigma, MO, USA). The outer well contained $600 \mu \mathrm{l}$ of culture medium. After 7 days, medium from the inner well was removed and medium from the outer well was replaced with Ultroser G medium [1:1 mixture of DMEM and Ham's F12 with $1 \%$ penicillin-streptomycin, 2\% Ultroser G serum (\#15950-017, Pall Corporation, Dreieich, Germany)]. After 30 days of culture, murine trachea epithelial cells were used for experiments. TER was measured using the Millicell ${ }^{\circledR}$ electrical resistance system (ERS) (Millipore, Darmstadt, Germany).

\section{Preparation of Single-Cell Suspensions}

For analysis of lung homogenate by qPCR, lungs were perfused through the right ventricle with PBS. Once lungs appeared white, they were removed and sectioned. Dissected lung tissue was then incubated with Liberase ${ }^{\mathrm{TM}}(100 \mu \mathrm{g} / \mathrm{ml}$, \#5401119001, Roche, Basel, Switzerland) and DNaseI (200 $\mu \mathrm{g} / \mathrm{ml}$, \#11284932001, Sigma, MO, USA) at $37^{\circ} \mathrm{C}$ for $1 \mathrm{~h}$. Digested lung tissue was gently disrupted by passage through a $19-\mathrm{G}$ needle and afterward through a $70-\mu \mathrm{m}$ pore size nylon cell strainer. Red blood cells were lysed using Red blood cell lysis buffer (eBioscience, CA,

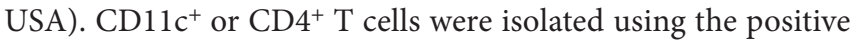

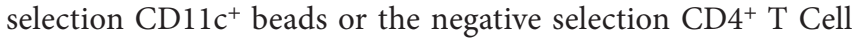
Isolation Kit (Miltenyi Biotec, Bergisch Gladbach, Germany), respectively. Magnetically labeled cells were isolated via the autoMACS Separator (Miltenyi Biotec). For single cell suspension of splenocytes, spleens were dissected and treated as described above without enzymatic digestion.

\section{T Cell Differentiation}

$\mathrm{CD}^{+} \mathrm{T}$ cells were isolated from a single cell suspension as described above. $1 \times 10^{5}$ cells per well were plated in 96-well round bottom plate in $100 \mu \mathrm{l}$ RPMI plus $\beta$-mercaptoethanol $(50 \mu \mathrm{M})$ and stimulated with $4 \mu \mathrm{l}$ anti-CD3 and anti-CD28coated beads (\#11456D, ThermoFisher Scientific, Waltham, MA, USA) + 20 ng/ml IL-2 (\#402-ML-020, R\&D Systems, Minneapolis, MN, USA), and either RPMI only (T0) or a Th2 differentiation solution consisting of $100 \mathrm{ng} / \mathrm{ml} \mathrm{IL-4} \mathrm{( \# 214-14,}$ Peprotech, Hamburg, Germany), $10 \mu \mathrm{g} / \mathrm{ml}$ anti-IFN $\gamma$ (\#517903, BioLegend, San Diego, CA, USA), and $10 \mu \mathrm{g} / \mathrm{ml}$ anti-IL-12 (\#505203, BioLegend, San Diego, CA, USA). Afterward, cells were incubated for 3 days at $37^{\circ} \mathrm{C}$. On day 4 , T cells were restimulated with a cell stimulation cocktail including PMA and ionomycin (\#00-4970, eBioscience, CA, USA) for $3 \mathrm{~h}$ and RNA was extracted.

\section{NFkB p65 Activity Assay}

$\mathrm{NF \kappa B}$ activity was measured in $1 \times 10^{6}$ cells of a lung homogenate by the TransAM ${ }^{\mathrm{TM}}$ NFkB p65 protein assay (Active Motif, Carlsbad, CA, USA), an ELISA-based method designed to specifically detect and quantify $\mathrm{NF \kappa B}$ p65 subunit activation. As a positive control, Raji nuclear extract was used that was 
provided with the kit. Wild-type oligonucleotides were used as an internal specificity control. The assay was performed according to the manufacturer's protocol and analyzed using a microplate absorbance reader (Sunrise reader, Tecan, Salzburg, Austria).

\section{Histopathological Analysis}

Organs were fixed via a tracheal canula under constant pressure of $20 \mathrm{~cm} \mathrm{H} \mathrm{H}_{2} \mathrm{O}$ using $4 \%$ (w/v) phosphate buffered paraformaldehyde overnight. Tissues were embedded in paraffin. For analysis of lung inflammation, $2 \mu \mathrm{m}$ sections were stained with periodic acid-Schiff (PAS) or with hematoxylin and eosin (H\&E), respectively.

\section{Statistics}

All experiments were repeated three times unless stated otherwise. Data are shown as mean + SD. Statistical significance of comparison between two groups was determined by two-tailed unpaired Student's $t$-test (for data sets following Gaussian distribution), Wilcoxon matched pairs test (for data sets not following Gaussian distribution), or two-way ANOVA including Bonferroni post-test (for multiple comparisons). All statistical analyses were done using GraphPad Prism (GraphPad 6.05, San Diego, CA, USA) software. Differences were considered significant at ${ }^{\star} p<0.05$, ${ }^{* *} p<0.01$, and ${ }^{* *} p<0.001$.

\section{RESULTS}

\section{SOCS1 1 NLS Is Localized in the Cytoplasm}

It has been shown that SOCS1 is able to translocate into the cell nucleus due to a functional NLS localized between the SH2 domain and the SOCS-box (amino acid 159-173) $(33,34)$. Confirming these results with murine SOCS1 constructs, NIH3T3 cells transiently transfected with murine eGFP-Socs 1 showed nuclear localization of the GFP-tagged protein. In contrast, eGFP-SOCS1 $\triangle$ NLS, in which the NLS has been replaced by the murine SOCS3 sequence (33), was localized more in the cytoplasm (Figure 1A). Cells transfected with Socs 1wt were also stimulated with IFN $\gamma$. Upon stimulation enhanced fluorescence in the cytoplasm could be observed, suggesting that SOCS1 is partly translocating out of the nucleus to inhibit signaling in the cytoplasm (Figure 1B). To verify that SOCS1 $\Delta$ NLS is still functional in the cytoplasm, inhibition of IFN $\gamma$ signaling was analyzed by Western Blotting. Therefore, the murine macrophage cell line Raw264.7 was transiently transfected with eGFP, eGFP-Socs1, or eGFP-Socs $1 \Delta N L S$. Tyrosine phosphorylation of STAT1 was examined upon treatment with IFN $\gamma$ 1-6 h post-transfection (Figures 1C,D). Already $1 \mathrm{~h}$ after IFN $\gamma$ treatment, eGFP-Socs 1 or eGFP-Socs $1 \Delta N L S$ transfected cells showed lower levels of phosphorylated STAT1 (59 or $57 \%$ as compared to eGFP transfected cells $1 \mathrm{~h}$ after IFN $\gamma$ stimulation). Importantly, we could not observe any differences in phosphorylated STAT1 levels between eGFP-Socs 1 and $e G F P$ Socs $1 \triangle N L S$-transfected cells. Data suggest that both SOCS1 and SOCS1 $\Delta$ NLS were effectively inhibiting IFN $\gamma$-induced STAT1 tyrosine phosphorylation, which occurs at the level of receptor activation.

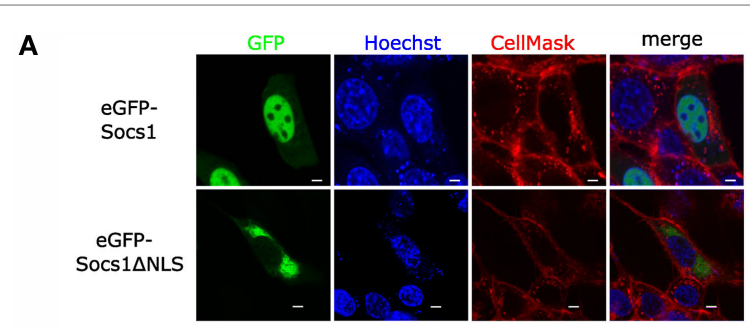

B
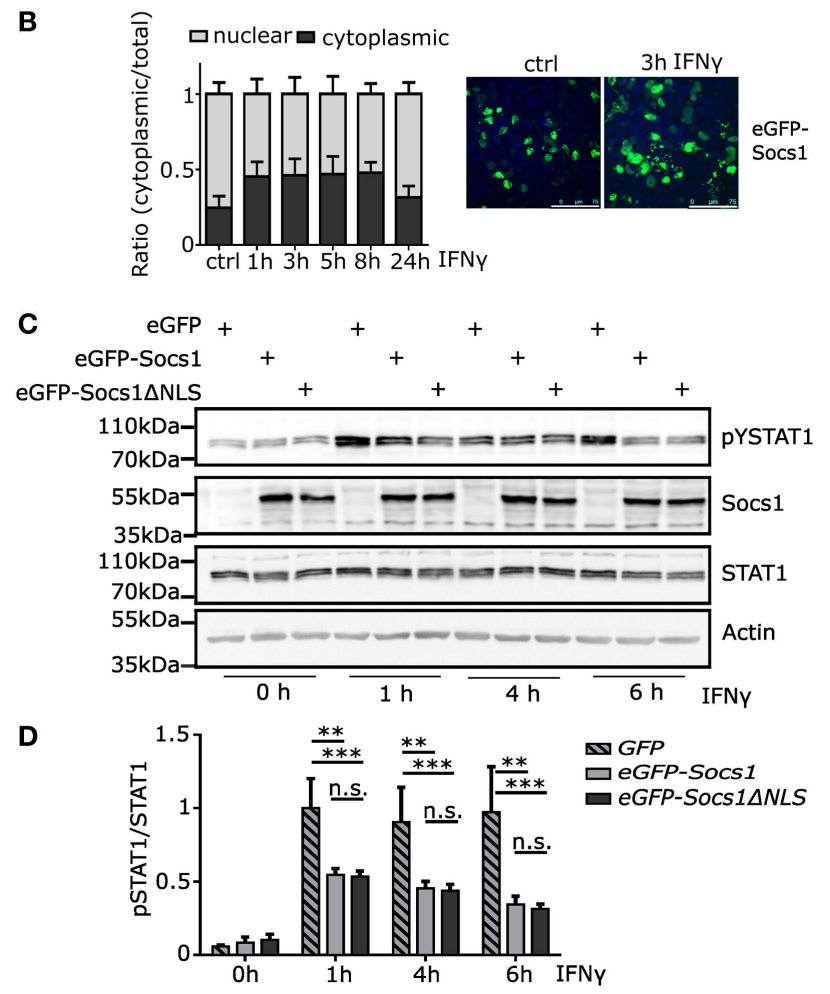

FIGURE 1 | Socs1 1 NLS is localized in the cytoplasm. (A) NIH3T3 cells were transfected with the indicated eGFP-tagged plasmids and visualized by confocal microscopy. Nuclei were counterstained with Hoechst, and membranes were stained with CellMask ${ }^{\mathrm{TM}}$ dye. Scale bar, $5 \mu \mathrm{m}$. (B) NIH3T3 cells were transfected with eGFP-Socs 1 and stimulated with IFN $\gamma(50 \mathrm{ng} / \mathrm{ml})$ as indicated. A z-stack was recorded and the ratio of the fluorescence in the cytoplasm versus the fluorescence in the nucleus was measured using Image J by setting an $\mathrm{ROI}$ around either the cytoplasm or the nucleus $(n=3$ with 20-50 cells each). Scale bar, $75 \mu \mathrm{m}$. (C) Western blot analysis of tyrosine phosphorylated STAT1. Raw264.7 cells were transfected with eGFP, eGFP-Socs 1, or eGFP-Socs $1 \triangle N L S$ and stimulated with IFN $\gamma(50 \mathrm{ng} / \mathrm{ml})$ as indicated. Protein extracts were stained for PY-STAT1 (Tyr701), SOCS1, STAT1, and $\beta$-actin. Quantification using ImageJ is shown in (D) $(n=3$, mean + SD, two-way ANOVA including Bonferroni post-test).

\section{Generation and Characterization of Mice Expressing Non-Nuclear SOCS1 1 NLS}

To analyze the function of SOCS1 in the cell nucleus in vivo, transgenic mice were established using a BAC containing a mutated Socs1 locus with non-nuclear Socs1 1 NLS, eGFP, and LuciferaseCBG99, termed MGL (Figure 2A). 2A peptide sequences between the protein coding regions result in three 


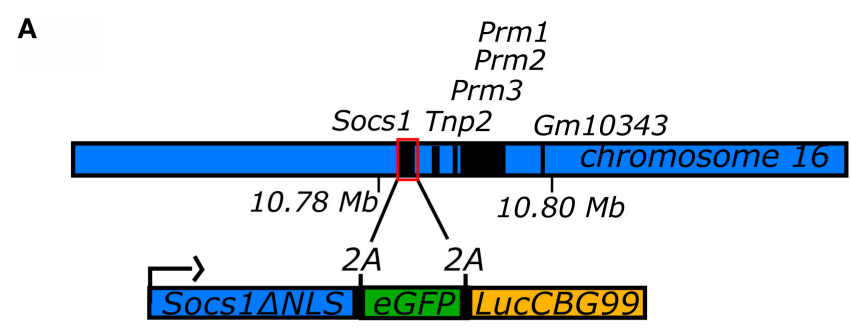

C

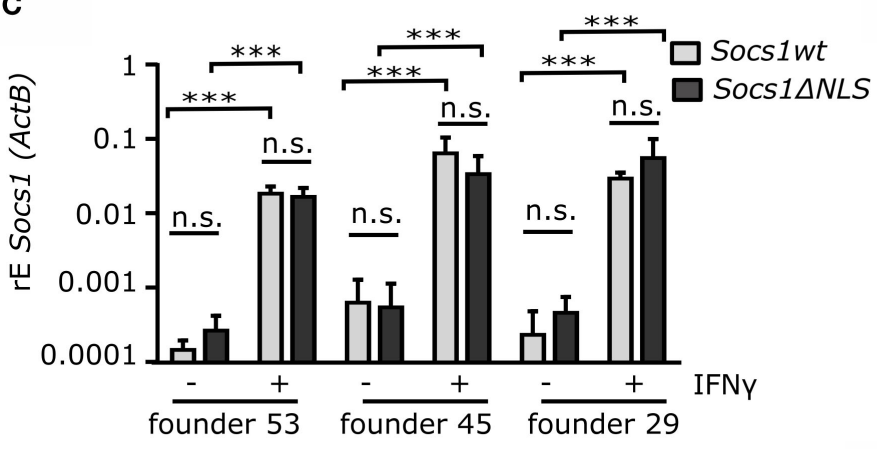

E

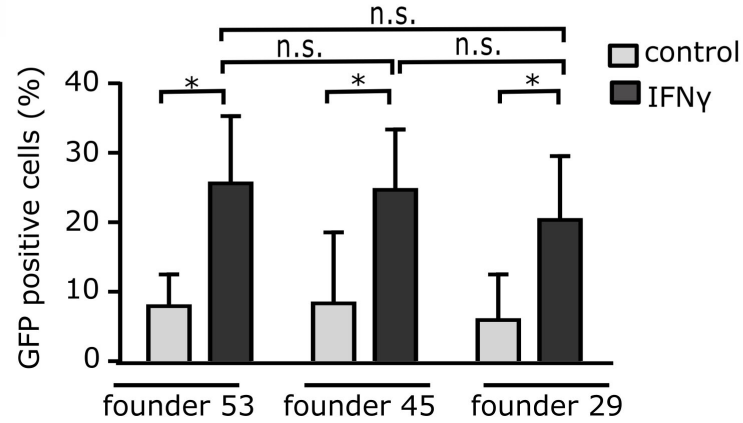

B

\begin{tabular}{|c|c|}
\hline $\begin{array}{r}\text { Detection of Socs } 1 w t: \\
\qquad \operatorname{Socs} 1\end{array}$ & $\mathrm{P} 1 \mapsto \leftrightarrow \bigsqcup^{\mathrm{P} 2}$ \\
\hline Detection of Socs $1 \triangle N L S$ : & $\mathrm{P} 1 \longmapsto \hookleftarrow^{\mathrm{P} 3}$ \\
\hline SoCS1 $1 \triangle N L S$ & \\
\hline Detection of total Socs1: & $\mathrm{P} 1 \longmapsto$ \\
\hline Socs 1 & INLS \\
\hline & $\mathrm{P} 1 \mapsto$ \\
\hline
\end{tabular}

D

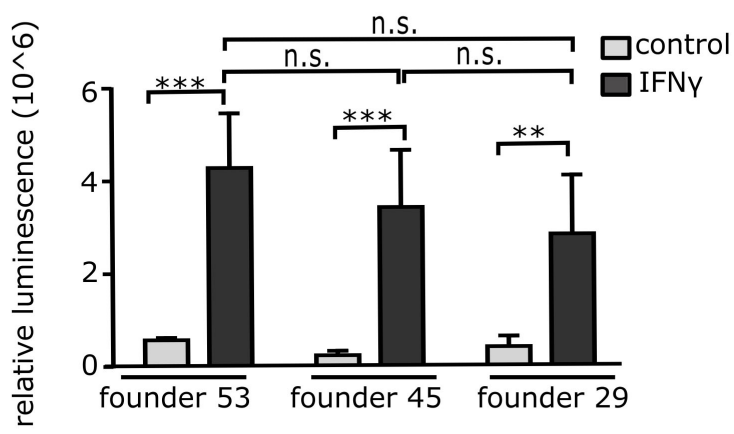

F

$\square$ Socs1-/- MGLtg

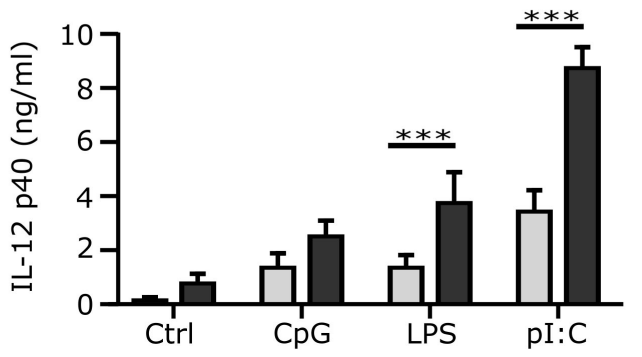

FIGURE 2 | Generation of Socs1 1 NLS transgenic mice. (A) Schematic drawing of the bacterial artificial chromosome (BAC) consisting of a mutated Socs1 locus containing Socs1 $\mathrm{NLS}$, eGFP, and LuciferaseCBG99. 2A sequences result in cleavage of the polyprotein. (B) qPCR strategy to specifically detect Socs1 wildtype (wt) using the primer P1 and P2 in combination with a labeled probe within the NLS, Socs $1 \Delta$ NLS using the reverse primer P3 in the NLS or total Socs 1 using the primer P1 and P2. BMMs of Socs $1^{+/+} M G L^{t g}$ mice of three different founders were stimulated with IFN $\gamma$ (50 ng/ml) for $24 \mathrm{~h}$ and analyzed for (C) $\mathrm{mRNA}$ expression of Socs 1 wt and Socs $1 \Delta N L S$, (D) luciferase activity, and (E) the percentage of GFP positive cells $(n=4-5$, mean + SD, two-way ANOVA including Bonferroni post-test). (F) CD11 c cells were isolated from lung homogenate and stimulated with CpG (1 $\mu \mathrm{M}), \mathrm{LPS}(100 \mathrm{ng} / \mathrm{ml})$, and pl:C (10 $\mu \mathrm{g} / \mathrm{ml})$ for $24 \mathrm{~h}$. $\mathrm{IL}-12 \mathrm{p} 40$ protein levels were measured by ELISA $(n=3-5$, mean $+\mathrm{SD}$, two-way ANOVA including Bonferroni post-test).

separate proteins. Thereby, 21 amino acids remain at the C-terminus of SOCS1 1 NLS. The combined expression of GFP and luciferase together with SOCS1 allows using these mice as reporter mice as well. Quantitative real-time PCR was established to confirm mRNA expression of Socs $1 \Delta N L S$ in bone marrow-derived macrophages (BMMs) from BAC transgenic mice (Figure 2B). To exclude founder-specific effects due to different integration sites of the BAC, stable expression and regulation of the mutated Socs 1 locus was examined in different founders. Therefore, offsprings of the founders \#53, \#45, and $\# 29$ were analyzed with respect to the expression of Socs1 and Socs $1 \Delta N L S$ in BMMs upon stimulation with IFN $\gamma$ for $24 \mathrm{~h}$ using the qPCR strategy as described in Figure 2B. After stimulation with IFN $\gamma$, mRNA expression of both Socs 1 and Socs $1 \Delta N L S$ were induced to a similar amount in all three founders (Figure 2C). We observed no differences in expression levels of Socs $1 w t$ and Socs $1 \Delta N L S$. Due to reporter functions of the mutated Socs 1 locus, luciferase assay was performed in BMMs after stimulation with IFN $\gamma$, showing similar luciferase activity in BMMs for the three founders (Figure 2D). In addition, GFP positive BMMs were analyzed by flow cytometry (Figure 2E). There was an increase in the percentage of GFP-positive cells after stimulation with IFN $\gamma$, and this was similar for founders \#53 (26\% \pm 9.6$)$, $\# 45(25 \% \pm 8.7)$, and \#29 $(21 \% \pm 9.2)$. Taken together, all three founders showed similar expression levels of the mutated Socs 1 locus. Mutant Socs1 expression was also in the same range as 
Socs1 wild-type (wt) mRNA, suggesting that different integration sites did not influence expression of the BAC. Thus, we had no indication for a founder specific effect and, therefore, further experiments were performed using founder \#53 if not stated otherwise.

\section{Functional Impairment of NFKB Inhibition in Socs 1-l-MGL ${ }^{\text {tg }}$ Mice}

To analyze the function of SOCS1 in the cell nucleus, Socs1MGL ${ }^{\text {tg }}$ mice were mated with Socs $1^{+/-}$mice to generate Socs $1^{-/-} M G L^{\text {tg }}$ mice, expressing Socs1 1 NLS in an otherwise Socs1-deficient background. In order to show that Socs $1^{-/-} M G L^{\text {tg }}$ mice indeed lack SOCS1 in the cell nucleus, we tried staining of endogenous SOCS1 by immunohistochemistry. However, we could not find a sufficiently specific antibody that was not staining sections from Socs $1^{-/-}$mice (including newly generated antibodies). Therefore, we decided to do a functional approach to verify non-nuclear expression of Socs1MGL. It has been reported that nuclear SOCS1 limits NFKB signaling by degradation of the NFKB subunit p65 (38). To examine whether NFkB signaling is altered in Socs $1^{-/-} M G L^{\text {tg }}$ mice, CD $11 \mathrm{c}^{+}$cells were isolated from lungs and stimulated ex vivo with TLR agonists. Stimulation of $\mathrm{CD}_{11 \mathrm{c}^{+} \text {cells }}$ from Socs $1^{-/-} M G L^{\text {tg }}$ mice with CpG-DNA, LPS, and pI:C for $24 \mathrm{~h}$ led to an increased protein expression of IL-12p40 as compared

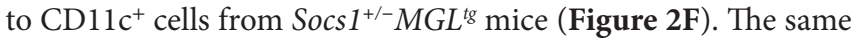
could be shown in CD11c cells isolated from spleens (Figure S1 in Supplementary Material). Data suggest sustained NFKB activation in Socs $1^{-/} M G L^{\text {tg }}$ mice that was confirmed by transcription factor binding assay for p65 (Figure S1 in Supplementary Material). We did not detect differences regarding TNF $\alpha$ protein levels (Figure S1 in Supplementary Material), which is in full accordance with previous findings (38) showing that only a subset of NFKB dependent genes is altered in Socs $1^{-/} M G L^{\text {tg }}$ mice. In contrast, IL-12p40 induction that needs prolonged binding of $\mathrm{NF \kappa B}$ to its promoter (44) was sensitive to SOCS1-induced NFKB inhibition. The results entirely phenocopy in vitro data using non-nuclear SOCS1 $1 \mathrm{NLS}$, suggesting that Socs $1^{-/-} M G L^{\text {tg }}$ mice functionally lack SOCS1 in the cell nucleus.

\section{Socs1 ${ }^{-1-}$ MGL ${ }^{\text {tg }}$ Mice Survive the Early Lethal Phenotype as Compared to Socs $1^{-/-}$ Mice}

Socs $1^{-/-}$mice die within $2-3$ weeks due to multiorgan inflammation (24-26). In contrast, Socs $1^{-/-} M G L^{\text {tg }}$ mice survived and showed no early lethality up to 60 days (Figure 3A), suggesting that lack of Socs $1 w t$ is rescued by Socs $1 \Delta N L S$. Socs $1^{+-}$mice also showed normal survival indicating that one allele of Socs 1 is sufficient for rescue of the severe knockout phenotype. In a small cohort $(n=4)$, survival of Socs $1^{-/} M G L^{\text {tg }}$ mice was recorded for an extended period (Figure S2A in Supplementary Material). Up to 38 weeks, Socs $1^{-/} M G L^{\text {tg }}$ mice appeared healthy without overt abnormalities. Although lethality was rescued in Socs $1^{-/-} M G L^{\text {tg }}$ mice, the mice showed reduced body weight both for female and male 8-week-old mice (Figure 3B) suggesting that lack of nuclear SOCS1 results in partial functional impairment. In the long-term survival cohort, Socs $1^{-/} M G L^{\text {tg }}$
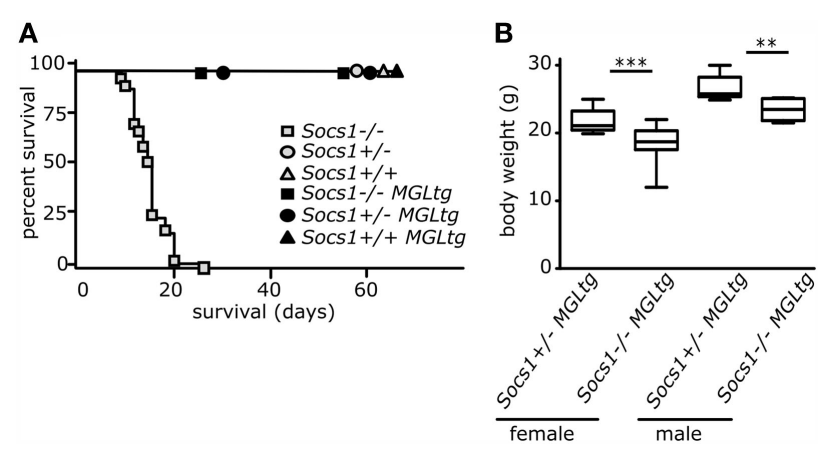

FIGURE 3 | Socs1-/-MGL ${ }^{\text {tg }}$ mice survive the early lethal phenotype of Socs $1^{-/-}$mice, but show a reduced body weight. (A) After mating Socs $1^{+/-}$to Socs $1^{+/-} M G L^{\text {tg }}$ mice, survival of offsprings was recorded to the age of 60 days ( $n=28-92$ mice per genotype). (B) Mouse body weight analysis ( $n=10-15$ 8-week-old mice per gender and genotype, mean $+\mathrm{SD}$, Wilcoxon matched pairs test).

mice showed slightly reduced body weight as well (Figure S2 in Supplementary Material).

\section{Similar mRNA Expression Levels, Protein Levels, and Protein Half-Life of SOCS1 and SOCS1 $\triangle$ NLS}

To verify that BMMs of Socs $1^{-/-} M G L^{\text {tg }}$ mice have similar expression levels of total Socs1 (both Socs1 and Socs1 1 NLS) as compared to BMMs of Socs $1^{+/-}$and Socs $1^{+/-} M G L^{\text {tg }}$ mice, cells were stimulated with IFN $\gamma$ for $24 \mathrm{~h}$ and $\mathrm{qPCR}$ was performed to detect mRNA of total Socs1 using the qPCR strategy as described in Figure 2B. Similar expression of total Socs 1 mRNA could be verified in BMMs of Socs $1^{-/-} M G L^{\text {tg }}$, Socs $1^{+/-}$, and Socs $1^{+/-} M G L^{\text {tg }}$ mice (Figure 4A). For further analysis, we generated a new SOCS1 antibody. This antibody did not detect a band with the expected molecular weight for SOCS1 in lysates of BMMs of Socs $1^{-/-}$mice (Figure 4B), thus proving specificity in Western Blot analysis. We confirmed expression of SOCS1 and SOCS1 1 NLS protein in lysates of BMMs of Socs $1^{+/-}$and Socs $1^{-/-} M G L^{\text {tg }}$ mice stimulated with IFN $\gamma$ for $6 \mathrm{~h}$. The higher molecular weight of SOCS1 $1 \Delta L S$ likely resulted from the additional 21 amino acids after cleavage of the $2 \mathrm{~A}$ sequence. In Figure 4C, quantification was done normalized to $\beta$-actin expression. Comparable protein levels for SOCS1 and SOCS1 1 NLS were detected (Figure 4B). The NLS of SOCS1 (RRMLGAPLRQRRVR) resembles a bipartite NLS composed of two basic stretches. Since the basic amino acid lysine is important for marking proteins for the ubiquitin proteasome pathway $(45,46)$, we addressed the question whether exchanging the NLS with the SOCS3 counterpart might alter protein half-life. We, therefore, performed a cycloheximide (CHX) chase experiment (Figures 4D,E). Six hours post stimulation with IFN $\gamma, \mathrm{CHX}$ was added to block nascent protein synthesis. Already after $4 \mathrm{~h}$ of CHX treatment, there was only $4 \%$ of the SOCS1 protein and $12 \%$ of the SOCS1 $\triangle$ NLS protein remaining. In summary, we did not observe alteration of mRNA expression levels, protein levels, or protein half-life upon mutating SOCS1 into SOCS1 1 NLS. 


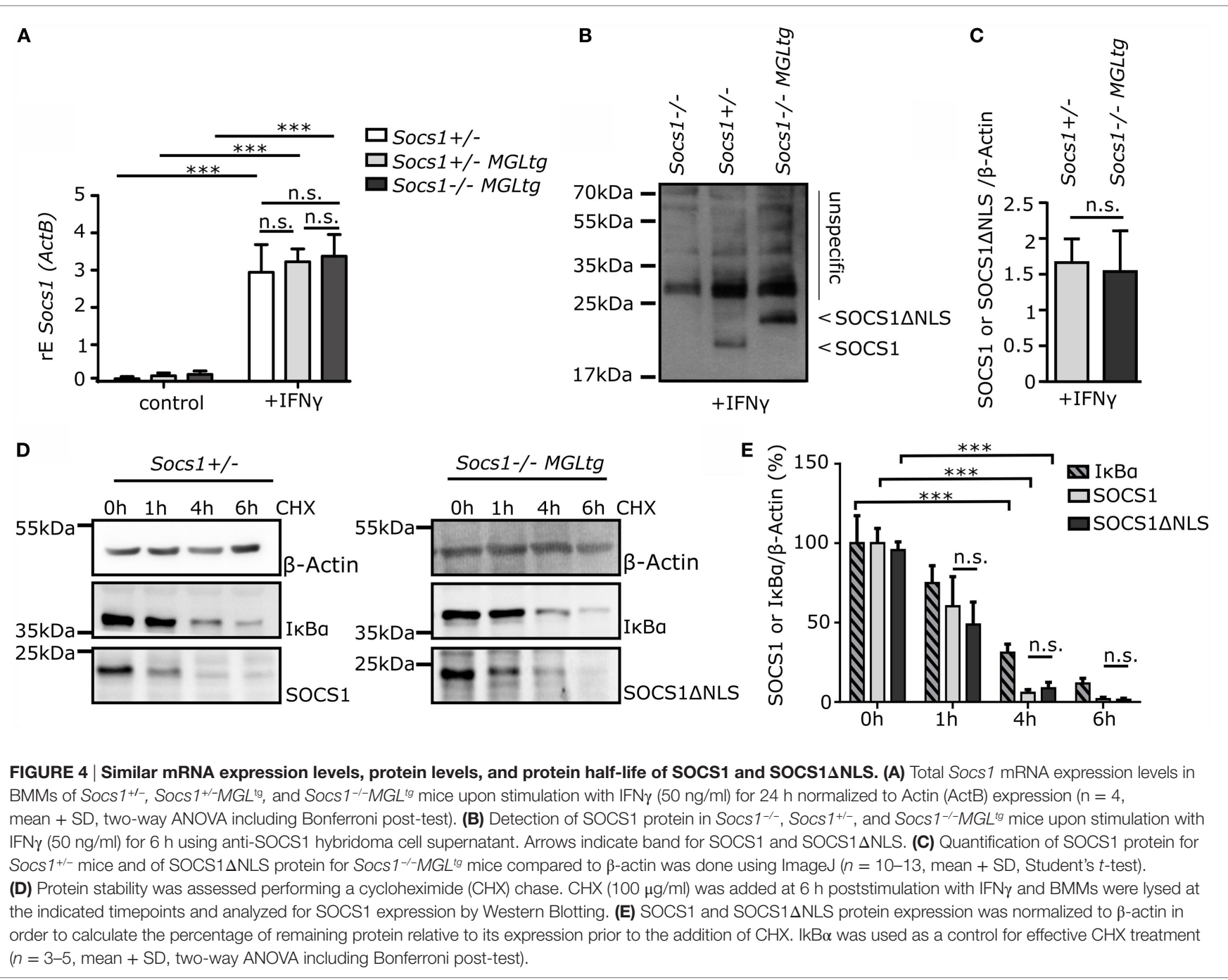

\section{Functional Regulation of Canonical IFN $\gamma$ Signaling in Socs 1-l-MGL ${ }^{\text {tg }}$ Mice}

Socs $1^{-/} M G L^{t g}$ mice survived the early lethal phenotype of Socs $1^{-/-}$mice (Figure 3A). As it is known that Socs $1^{-/-}$can be rescued by the administration of anti-IFN $\gamma$ antibodies in the neonatal period or by using Socs $1^{-/-} I F N \gamma^{-/-}$mice $(47,48)$, we hypothesized that canonical IFN $\gamma$ signaling is not altered in Socs $1^{-/-} M G L^{\text {tg }}$ mice. To test this hypothesis, tyrosine phosphorylation of STAT1 was examined in BMMs upon treatment with IFN $\gamma$ for 1-6 h (Figure 5A). IFN $\gamma$ signaling was prolonged in Socs $1^{-/-}$mice as shown by the sustained levels of phosphorylated STAT1. There was a decline in phosphorylated STAT1 levels for both Socs $1^{+-} M G L^{\text {tg }}$ mice (to 20\%) and Socs $1^{-1-} M G L^{\text {tg }}$ mice (to $22 \%$ ) already $4 \mathrm{~h}$ after IFN $\gamma$ stimulation as compared to $58 \%$ for Socs $1^{-/-}$mice (Figures 5A,B). No significant differences were observed between Socs $1^{+/-} M G L^{t g}$ and Socs $1^{-/-} M G L^{\text {tg }}$ mice. Analyzing mRNA expression levels of classical IFN $\gamma$ target genes, both $i N O S$ and $\operatorname{Irf} 9$ were induced upon stimulation with IFN $\gamma$ to a similar extent in Socs $1^{+/-} M G L^{\text {tg }}$ and $\operatorname{Socs} 1^{-/-} M G L^{\text {tg }}$ mice
(Figure 5C). Of note, the expression levels were also similar to Socs $1^{+/-}$mice, arguing against gene dosage effects. This allows interpretation of the data from Socs $1^{-/-} M G L^{\text {tg }}$ mice with regards to lack of nuclear SOCS1 and not altered concentration of cytoplasmic SOCS1. There was a minor, but non-significant, increase in the expression level of Icam- 1 after $6 \mathrm{~h}$ of stimulation in BMMs of Socs $1^{-1-} M G L^{\operatorname{tg}}$ mice. These findings indicate that SOCS $1 \Delta \mathrm{NLS}$ was still able to regulate cytoplasmic signaling pathways and that canonical IFN $\gamma$ signaling was not altered in Socs $1^{-/-} M G L^{t g}$ mice.

\section{Differential Expression of a Subset of Non-Canonical IFN $\gamma$ Target Genes by Socs 1-/-MGL ${ }^{\text {tg }}$ Mice}

To support the hypothesis that canonical IFN $\gamma$ signaling is not altered in Socs $1^{-/} M G L^{\text {tg }}$ mice, whole-genome expression analysis was performed. Therefore, BMMs were stimulated with IFN $\gamma$ for $24 \mathrm{~h}$ and RNA was extracted and subjected to whole-genome expression analysis. 1097 genes were differentially regulated between untreated and IFN $\gamma$ stimulated cells, but only 86 genes 
A
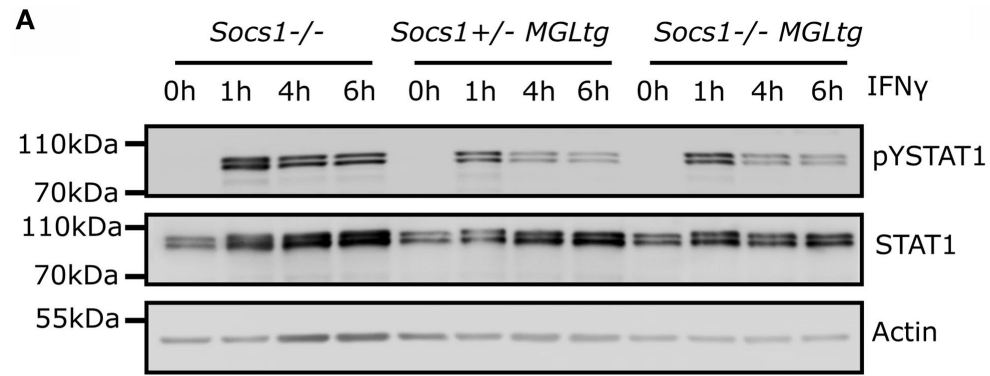

C

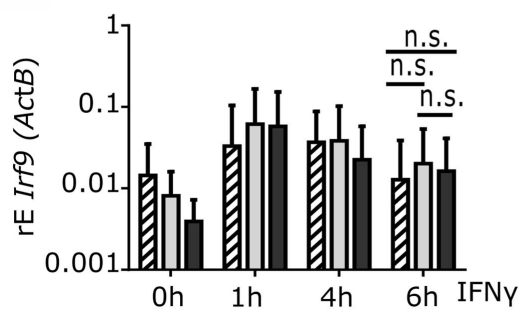

B

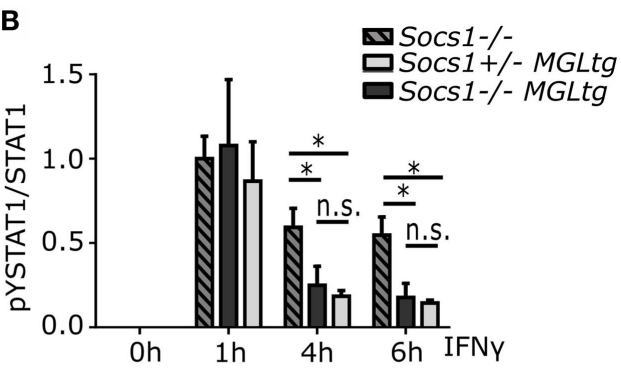

FIGURE 5 | Canonical IFN $\boldsymbol{\gamma}$ signaling is not altered in Socs $\mathbf{1}^{-/} \mathbf{M G L}^{\text {tg }}$ mice. (A) Western blot analysis of tyrosine phosphorylated STAT1 (Tyr701). STAT1 and $\beta$-actin were used as loading controls. Protein extracts were prepared from BMMs of Socs $1^{-/-}$, Socs $1^{+/-} M G L^{t g}$, and Socs $1^{-/-} M G L^{\text {tg }}$ mice that were treated with IFN $\gamma$ $(50 \mathrm{ng} / \mathrm{ml})$ as indicated. Quantification using ImageJ is shown in (B) $(n=4)$. (C) mRNA expression of interferon target genes iNOS, Irf9, and Icam-1 are shown normalized to Actin (ActB) expression in BMMs of Socs ${ }^{+/-}$, Socs $1^{+/-} \mathrm{MGL}^{\text {tg }}$, and Socs $1^{-/-} \mathrm{MGL}^{\text {tg }}$ mice treated with IFN $\gamma(50 \mathrm{ng} / \mathrm{ml})$ for $1-6 \mathrm{~h}(n=4)$. Mean $+\mathrm{SD}$ is presented for each group and significance was assessed using two-way ANOVA including Bonferroni post-test.

were differentially regulated between BMMs of Socs $1^{-/-} M G L^{\operatorname{tg}}$ mice and Socs $1^{+/-} M G L^{\text {tg }}$ mice. To analyze combinatorial patterns in an unbiased fashion, principal component analysis (PCA) was performed. Analysis of untreated BMMs of both genotypes revealed close correlation, whereas IFN $\gamma$ treated BMMs of Socs $1^{-/-} \mathrm{MGL}^{\text {tg }}$ mice and Socs $1^{+-} M G L^{\text {tg }}$ mice were found to be more separated (Figure 6A). Most differentially regulated genes were induced rather than repressed in $\operatorname{Socs}^{-1-} M G L^{\text {tg }}$ mice (Figures 6B,C). The top 10 differentially regulated genes (Figure 6D) included significantly higher expressed genes in BMMs of Socs $1^{-/-} M G L^{\text {tg }}$ mice such as Indoleamine 2,3-Dioxygenase 1 (Indo, 11.47-fold) and SelectinL (Sell, 6.69-fold) as well as significantly lower expressed genes in BMMs of Socs $1^{-1-} \mathrm{MGL}^{\text {tg }}$ mice such as Src-Like-Adaptor (Sla, 0.29-fold) and Growth Differentiation Factor 3 (Gdf3, 0.26fold). Those genes were confirmed by qPCR to be differentially regulated in Socs $1^{-/-} M G L^{\text {tg }}$ mice (Figure 6E). Importantly, no canonical IFN $\gamma$ target genes were differentially regulated in Socs $1^{-/-} M G L^{\text {tg }}$ mice. Of note, we found 38 genes involved in $\mathrm{NF \kappa B}$ signaling to be upregulated in BMMs of Socs $1^{-/-} M G L^{t g}$ mice and 16 downregulated ones. Pathway annotation was performed using the PANTHER classification system among the 86 genes differentially regulated between IFN $\gamma$ treated BMMs of Socs $1^{+-} M G L^{\text {tg }}$ and Socs $1^{-/} M G L^{\text {tg }}$ mice (Table 1). Instead of IFN $\gamma$ signaling pathway, we found TLR and TNF signaling pathways to be dysregulated. For TLR signaling pathway, three genes assigned to the signaling pathway were significantly higher expressed and five were significantly lower expressed in BMMs of Socs $1^{-/-} M G L^{\text {tg }}$ mice. For TNF signaling pathway, five genes assigned to the signaling pathway were significantly higher expressed, whereas only one was significantly lower expressed in BMMs of Socs $1^{-/-} M G L^{\text {tg }}$ mice, arguing for a general induction of the pathway. Moreover, TFBS among the differentially regulated genes were analyzed using the overrepresentation analysis tool oPOSSUM (Table 2). TFBS for CTCF, IRF2, and NFKB were overrepresented among the differentially regulated genes in Socs $1^{-/} M G L^{\text {tg }}$ mice with 21, 8 , and 56 genes, respectively. STAT1 as classical transcription factor for IFN $\gamma$ signaling was not overrepresented among the differentially regulated genes, strengthening the hypothesis of functional regulation of canonical IFN $\gamma$ signaling by Socs $1 \Delta$ NLS in Socs $1^{-/-} M G L^{\text {tg }}$ mice. In summary, whole genome expression analysis revealed a small subset of non-canonical IFN $\gamma$-regulated genes that were differentially regulated in Socs $1^{-/-} M G L^{\operatorname{tg}}$ mice with an overrepresentation of TFBS for NFKB.

\section{Socs1 ${ }^{-I-} M$ ML $^{\text {tg }}$ Mice Spontaneously Develop Low-Grade Inflammation in the Lung}

Although inhibition of IFN $\gamma$ signaling by SOCS1 $1 \mathrm{NLS}$ was still functional in Socs $1^{-/-} M G L^{\text {tg }}$ mice, gene expression analysis indicated that differences due to lack of SOCS1 in the cell nucleus were present. We closely analyzed Socs $1^{-1-} M G L^{\text {tg }}$ mice for disease symptoms. Histopathological analysis revealed low-grade inflammation in lung and liver in a significant number of Socs ${ }^{-/-} M G L^{\text {tg }}$ mice (Table S2 in Supplementary Material). However, no differences were observed in serum AST and ALT levels (Figure S3 in Supplementary Material). We, therefore, focused on lung histopathology. Infiltrates in lung tissue were observed in $45 \%$ of the lung sections of Socs $1^{-/-} M G L^{\text {tg }}$ mice (Figure 7A) in three different founders. PAS staining was performed to identify mucus producing cells, revealing a higher number of PAS positive cells in the lungs of $\operatorname{Socs}^{-/-} M G L^{\text {tg }}$ mice (Figure 7B). In addition, 
A

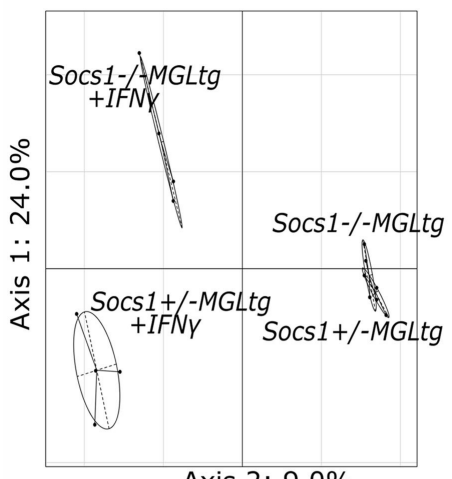

Axis $2: 9.0 \%$
B

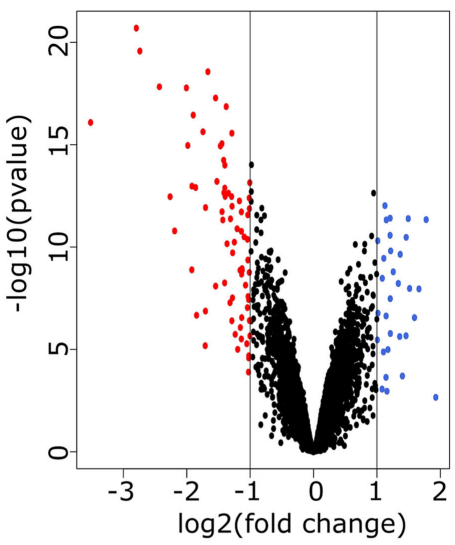

E
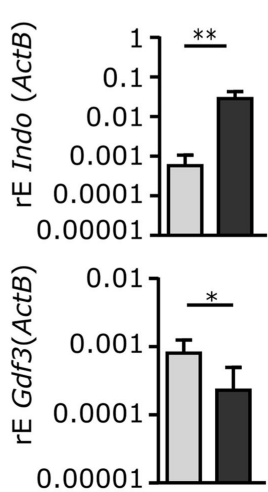

C

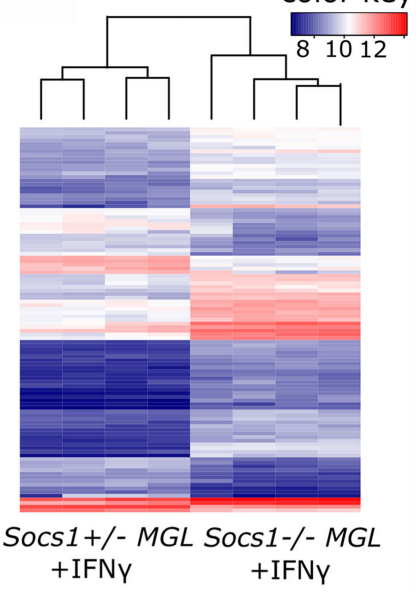

$\square$ Socs1+/- MGLtg

$\square$ Socs1-/- MGLtg
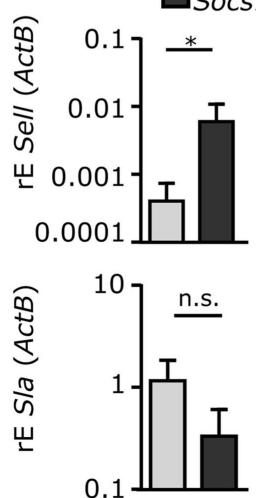

FIGURE 6 | Subset of non-classical IFN $\gamma$ target genes is differentially regulated in Socs 1/-MGL $^{\text {tg }}$ mice. BMMs were stimulated with IFN $\gamma$ for $24 \mathrm{~h}$, RNA was extracted and subjected to whole-genome expression analysis (A) principal component analysis (PCA). The two principal components and their fraction of the overall variability of the data (\%) are shown on the $x$-axis and the $y$-axis. Clusters of experiments are circled (95\% confidence interval ellipse) and annotated as

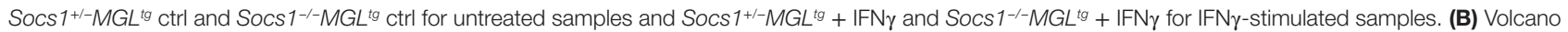
plot showing the genes that were differentially expressed between BMMs of Socs $1^{+/-} M G L^{\text {tg }}$ and Socs $1^{-1-} M G L^{\text {tg }}$ mice. Only significant values $(p \leq 0.05)$ were considered showing a log2-fold change $\leq-1$ (red points) or $\geq 1$ (blue points). (C) Heat map visualizing hierarchical clustering analysis based on the expression levels of genes that are differentially expressed between BMMs of Socs $1^{+/}-M G L^{\text {tg }}$ and Socs $1^{-/-} M G L^{\text {tg }}$ mice. Red indicates higher expression and blue indicates lower expression of the corresponding gene in Socs $1^{-1-}$ MGL ${ }^{\text {tg }}$ mice, respectively $(n=4)$. (D) 10 most prominently up- and downregulated genes according to their fold change. (E) Quantitative RT-PCR was performed using RNA from BMMs stimulated with IFN $\gamma$ for $24 \mathrm{~h}(n=3$, mean + SD, Student's $t$-test).

TABLE 1 | Pathway annotation [protein analysis through evolutionary relationships (PANTHER) classification system].

\begin{tabular}{lclll}
\hline Pathway ID & Input/background & Induced genes & Repressed genes & $\boldsymbol{p}$-Value \\
\hline TLR signaling pathway & $8 / 101$ & CD40, Cxcl10, Jun & Cc/3, Cc/4, Cc/5, T/r7, T/r8 \\
TNF signaling pathway & $6 / 109$ & Socs3, Fas, Tnfaip3, Cxc/10, Jun & CC/5 & 0.00129
\end{tabular}

Differentially expressed genes in Socs 1--MGL ${ }^{\text {tg }}$ mice upon IFNy stimulation showing a log2-fold change $(\leq-1$ or $\geq 1)$ and $p \leq 0.05$ were analyzed to classify and identify gene functions.

TABLE 2 | oPOSSUM analysis of overrepresented transcription factor binding sites.

\begin{tabular}{|c|c|c|c|c|c|}
\hline TFBS & Input/background & Class & Family & z-score & Fischer score \\
\hline CTCF & $21 / 86$ & Zinc coordinating & $\beta \beta \alpha$ zinc finger & 14.88 & 5.01 \\
\hline IRF2 & $8 / 86$ & Winged helix-turn-helix & IRF & 14.343 & 4.42 \\
\hline$N F_{\kappa} B$ & $56 / 86$ & $\lg$ fold & Rel & 12.24 & 2.28 \\
\hline
\end{tabular}

Differentially expressed genes in Socs $1^{-/-}$MGL ${ }^{\text {tg }}$ mice upon IFN $\gamma$ stimulation showing a log2-fold change $(\leq-1$ or $\geq 1)$ and $p \leq 0.05$ were uploaded to identify overrepresented transcription factor binding sites among those genes. Transcription factors enriched in the corresponding gene set were CTCF, IRF2, and NFkB. 
Socs $1^{-1-} M G L^{\text {tg }}$ mice showed 19.4-fold increased serum IgE levels (Figure 7C). Since SOCS1 has been shown to be important for $\mathrm{T}$ helper cell differentiation $(31,49,50)$, we analyzed whether Socs $1^{-1-} M G L^{\text {tg }}$ mice have a $\mathrm{T}$ helper cell bias. Therefore, $\mathrm{CD} 4^{+}$ $\mathrm{T}$ cells were isolated from lung homogenates and expression of transcription factors for $\mathrm{T}$ helper cell subsets was examined by qPCR (Figure 7D). Socs $1^{-/} M G L^{\text {tg }}$ mice showed a 4.2 -fold increase of Gata $^{+}$cells, suggesting a higher number of Th2 cells. Using an in vitro differentiation assay, naive $\mathrm{CD} 4^{+} \mathrm{T}$ cells from Socs $1^{-/} M G L^{\text {tg }}$ mice tend to express more Gata3 as compared

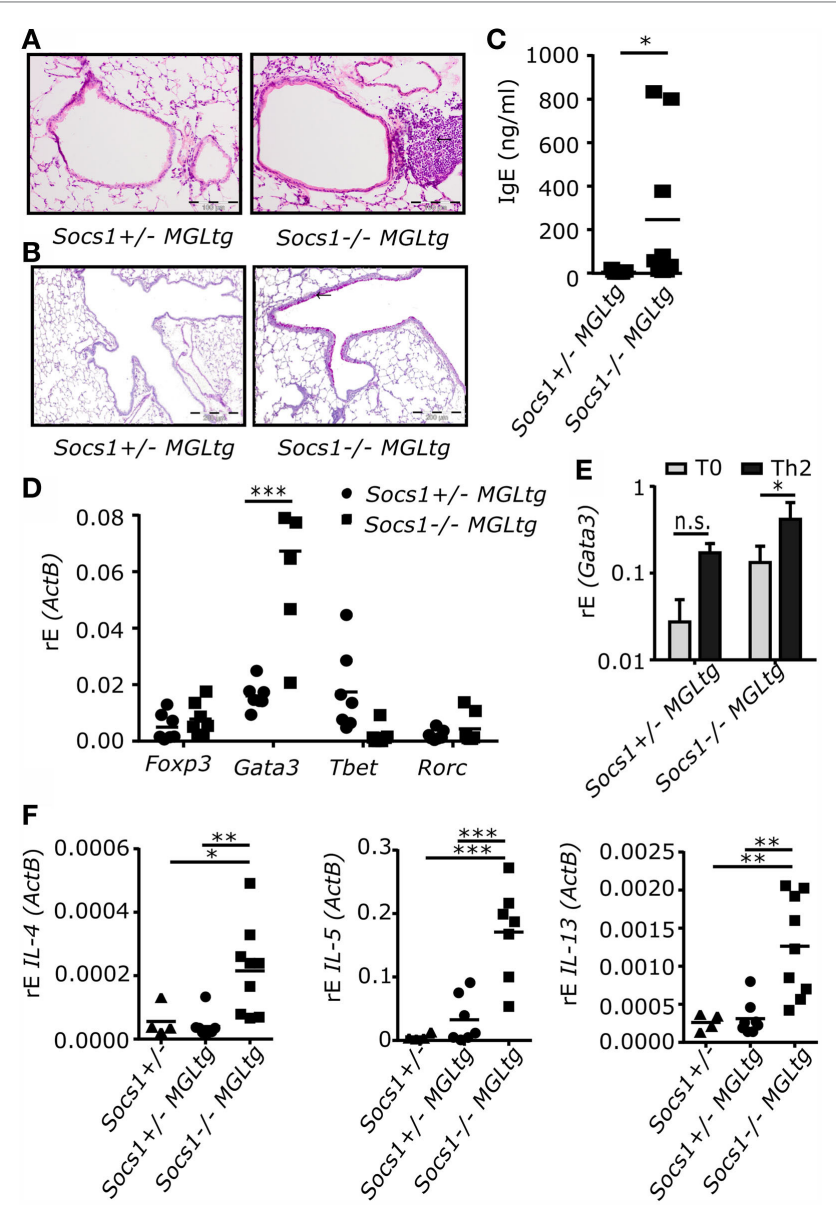

FIGURE 7 | Socs1 ${ }^{-/}$MGL ${ }^{\text {tg }}$ mice show low-grade inflammation in the lung. (A) H\&E-stained airway cross sections. Arrow highlighting infiltrating cells. Scale bar, $100 \mu \mathrm{m}$. One lung section per mouse was analyzed. (B) Periodic acid-Schiff (PAS) stained airway cross sections. Arrow highlighting PAS positive cells. Scale bar, $200 \mu \mathrm{m}$. (C) IgE concentration in serum ( $n=9$, mean $+\mathrm{SD}$, Wilcoxon matched pairs test). (D) Expression levels of Foxp3, Gata3, Tbet, and Rorc in sorted $C D 4^{+} \mathrm{T}$ cells in the lung of both founder \#53 and \#29 ( $n=7-11$, mean + SD, two-way ANOVA including Bonferroni post-test). (E) Naive CD4 ${ }^{+} T$ cells were differentiated under $T_{0}$ conditions (RPMl only) or under Th2 conditions (100 ng/ml IL-4, $10 \mu \mathrm{g} / \mathrm{ml}$ anti-IFN $\gamma$, and $10 \mu \mathrm{g} / \mathrm{ml}$ anti-IL-12p40) for 3 days and restimulated using PMA and ionomycin. Expression of Gata3 was examined by qPCR ( $n=3$, mean + SD, two-way ANOVA including Bonferroni post-test). (F) Expression levels of $I L-4, I L-5$, and $/ L-13$ in total lung homogenates of both founder \#53 and \#29 ( $n=7-11$, mean + SD, one-way ANOVA including Bonferroni post-test). to $\mathrm{CD}^{+} \mathrm{T}$ cells from Socs $1^{+/-} M G L^{\text {tg }}$ mice, even under neutral conditions ( $\mathrm{T}_{0}$, RPMI only) (Figure 7E). Increased mRNA expression of $I L-4, I L-5$, and $I L-13$ in complete lung homogenates of Socs $1^{-/-} M G L^{\text {tg }}$ mice compared to both Socs ${ }^{+/-} \mathrm{MGL}^{\text {tg }}$ and Socs ${ }^{+/-}$ mice confirmed this Th2 bias (Figure 7F). Notably, we found one population of Socs $1^{-1-} M G L^{t g}$ mice with a strong expression of Gata3 and Th2 type cytokines in lung homogenates, and the second population showing a weaker Th2 bias, consistent with the fact that we could observe infiltrates in the lung only in $45 \%$ of the mice.

\section{Increased Airway Eosinophilia in Socs $1^{-/} M G L^{\text {tg }}$ Mice in an OVA Experimental Asthma Model}

To analyze if this Th2 bias is of physiological relevance, mice were challenged by inhaled antigen. Socs $1^{-/-} M G L^{\text {tg }}$ mice were subjected to a well-established protocol for the induction of experimental asthma $(41,51)$. Upon OVA sensitization and OVA aerosol challenge, Socs $1^{-/} M G L^{\text {tg }}$ mice showed increased airway eosinophilia $\left(21.5 \times 10^{4}\right.$ cells/ml in BALF) as compared to Socs $1^{+/-} M G L^{\text {tg }}$ control mice $\left(7.3 \times 10^{4}\right.$ cells $/ \mathrm{ml}$ in BALF $)$ (Figure 8A). In addition, IL-4 and IL-13 levels were higher in BAL fluid of Socs $1^{-/-} M G L^{\text {tg }}$ mice upon OVA sensitization and challenge as compared to Socs $1^{+/-} M G L^{\text {tg }}$ mice (Figure 8B). IL-5

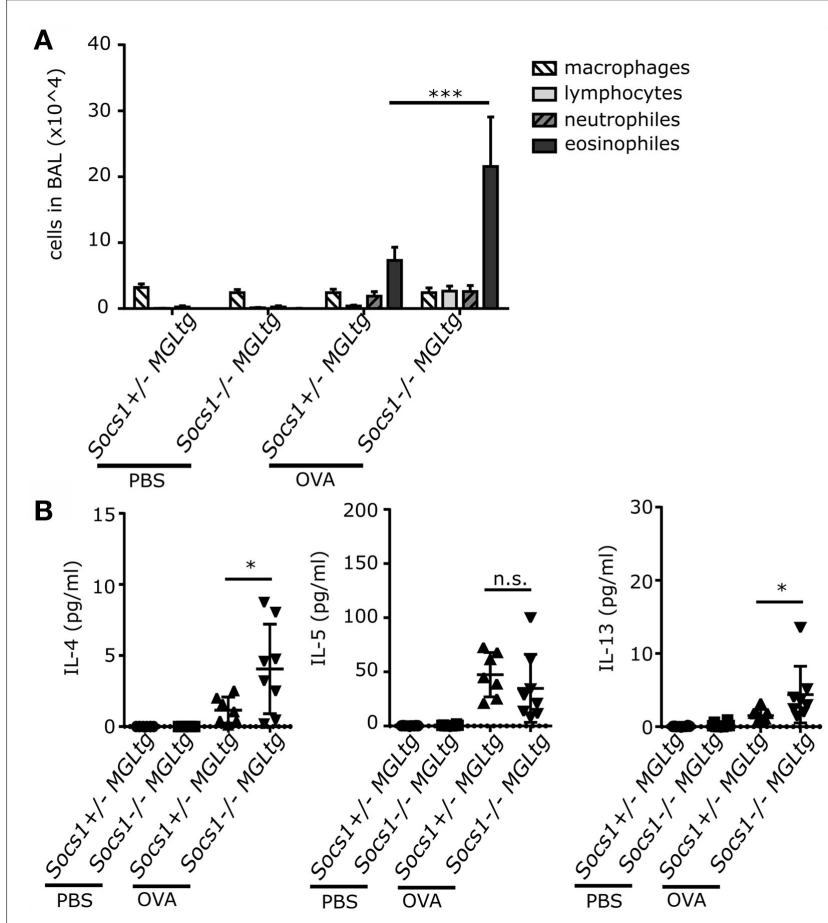

FIGURE 8 | Enhanced airway eosinophilia in Socs $1^{-/}-M^{\text {G }} L^{\text {tg }}$ mice upon OVA sensitization and challenge. Mice were sensitized with OVAVAlum or PBS i.p. on days 1, 14, and 21, followed by a challenge with 1\% OVA aeroso or PBS on days 26, 27, and 28. (A) Total numbers of leukocyte subpopulations in BAL fluids are represented. (B) Levels of IL-4, IL-5, and $\mathrm{IL}-13$ in serum were measured by ELISA $(n=6-8$, mean + SEM, two-way ANOVA including Bonferroni post-test). 
levels upon challenge were induced, yet, showed no difference with respect to expression of the non-nuclear SOCS1. Similar effects were observed in Socs $1^{-/} M G L^{\text {tg }}$ mice upon intratracheal IL-13 instillation. IL-13-treated mice of all genotypes developed neutrophilia in the lung. Socs $1^{-/-} M G L^{\text {tg }}$ mice additionally showed enhanced influx of eosinophils (however non-significant) and lymphocytes (Figure S4A in Supplementary Material). In addition, Socs $1^{-/-} M G L^{t g}$ mice showed increased mRNA expression of IL-4, IL-5, and IL-13, which was even more pronounced upon IL-13 treatment. Socs 1 induction in all three genotypes upon IL-13 instillation was equal (Figure S4B in Supplementary Material).

\section{Disrupted Epithelial Integrity in Socs1 ${ }^{-1-}$ MGL $^{\text {tg }}$ Mice}

Since Socs $1^{-/-} M G L^{\text {tg }}$ mice showed enhanced expression of IL-25, IL-33, and Tslp in lung homogenates (Figure 9A), we closer analyzed the airway epithelium. Therefore, tracheas were isolated and trachea epithelial cells were differentiated in an air-liquid interface (ALI) using transwells. Increased IL-33 expression could be verified in isolated trachea epithelial cells from Socs $1^{-/} M G L^{\text {tg }}$ mice. In addition, Ccl26 expression was examined since it is known for the recruitment of eosinophils (52). Indeed, trachea epithelial cells from Socs $1^{-/} M G L^{\text {tg }}$ mice expressed significantly

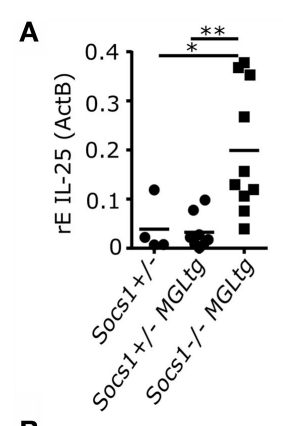

B

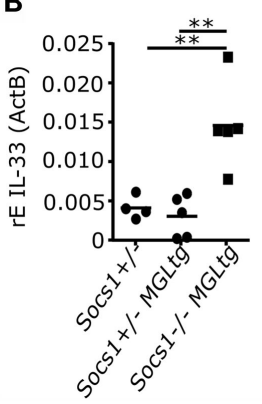

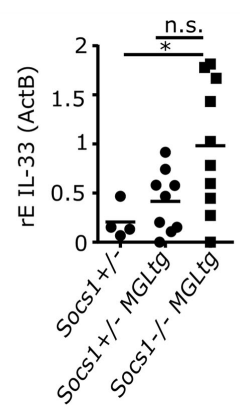

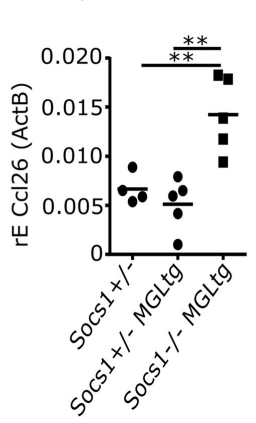

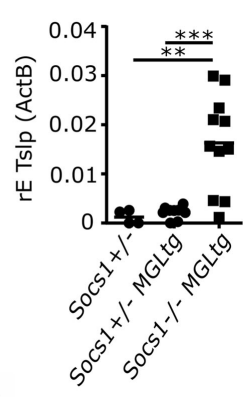

C

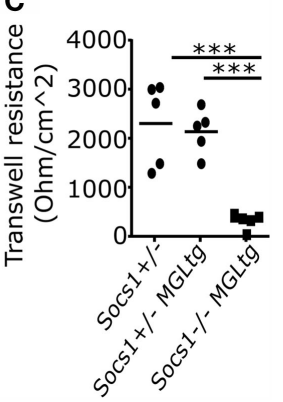

FIGURE 9 | Trachea epithelial cells from Socs1 ${ }^{-/-} M G L^{\text {tg }}$ mice show alterations. (A) Enhanced expression levels of $I L-25, I L-33$, and Ts/p in total lung homogenates of both founder \#53 and \#29 ( $n=7-11$, mean $+\mathrm{SD}$, oneway ANOVA including Bonferroni post-test). (B) Enhanced expression levels of $I L-33$ and Cc/26 in primary murine trachea epithelial cells $(n=5$, mean + SD, one-way ANOVA including Bonferroni post-test). (C) Decreased transepithelial electrical resistance in trachea epithelial cells from Socs $1^{-1-} M G L^{\text {tg }}$ mice as measured with the Millicell ${ }^{\circledR}$ electrical resistance system (ERS) $(n=5$, mean $+\mathrm{SD}$, one-way ANOVA including Bonferroni posttest). more Ccl26 as compared to cells from Socs $1^{+/-} M G L^{\text {tg }}$ mice. Interestingly, we found decreased TER in trachea epithelial cells from Socs $1^{-/-} M G L^{\text {tg }}$ mice as compared to cells from Socs $1^{+/-}$and Socs $1^{+/-} M G L^{\text {tg }}$ mice. This suggests disrupted epithelial integrity and might explain low-grade inflammation observed in the lungs of Socs $1^{-/-} M G L^{\text {tg }}$ mice.

\section{DISCUSSION}

Suppressor of cytokine signaling 1 is a classical negative feedback regulator of cytoplasmic JAK/STAT signaling (4-6). However, it has been described that SOCS1 is also localized in the cell nucleus $(33,34)$, yet, the function of SOCS1 in the cell nucleus in vivo remains elusive. To study the role of nuclear SOCS1, we generated transgenic mice using a BAC containing a mutated Socs1 (Socs1 $1 \Delta L S$ ) that fails to translocate in the cell nucleus, which is expressed together with eGFP and LuciferaseCBG99 $(M G L)$. Using BACs to create transgenic mice is a commonly used approach (53-56), which allows manipulating genes embedded within their genetic regulatory environment. We aimed for similar gene regulation of Socs1wt and Socs1 1 NLS and therefore carefully controlled that the locus of BAC-vector integration produced similar transcript amounts of Socs1wt and Socs $1 \Delta N L S$ (Figure 4). There were no detectable differences regarding expression and regulation of Socs1wt or Socs1 1 NLS mRNA between three different founders (Figure 2). Next, we investigated whether there is a gene dosage effect. We cannot fully exclude that increased localization of SOCS $1 \Delta$ NLS to the cytoplasm contributes to the observed effects although we did not find any indication that this construct is more effective in inhibiting JAK/STAT signaling. In fact, data from Socs $1^{+/-}$and Socs $1^{+/} M G L^{\text {tg }}$ mice were very similar, thus arguing against any side effect due to increased cytoplasmic localization of SOCS1 1 NLS. In contrast to Socs $1^{-/-}$mice, Socs $1^{+/-}$mice lacked pathological levels of IFN $\gamma$ (24) and were found to be phenotypically normal (26). We confirm these data by showing that Socs $1^{+/-}$mice had normal survival (Figure 3) indicating that one allele of Socs 1 is sufficient for rescue of the severe knockout phenotype. Analyzing expression of IFN $\gamma$-dependent genes (Figure 5) and the lung phenotype (Figures 7 and 9), we found no difference between Socs $1^{+/-}$and Socs $1^{+/-} M G L^{\text {tg }}$ mice, arguing against a gene dosage effect and for a localization-specific effect resulting in eosinophilic lung inflammation in Socs $1^{-/-} M G L^{\text {tg }}$ mice. As reported previously, we found that SOCS1 is expressed at low levels and is relatively short-lived (57), but can be induced by IFN $\gamma$ (49). The NLS of SOCS1 (RRMLGAPLRQRRVR, amino acid 159-173) resembles a bipartite NLS composed of two basic stretches. Lysine as a basic amino acid is important for the ubiquitin proteasome pathway, linking ubiquitin chains onto proteins to mark them for degradation via the proteasome $(45,46)$. Therefore, we addressed the question whether exchanging the NLS with the SOCS3 counterpart might alter protein half-life (Figures 4D,E). However, protein half-life was not altered upon exchanging the NLS corresponding part of SOCS1 with SOCS3 (SOCS1 1 NLS). In general, the results confirm previously described expression patterns of SOCS1, indicating that the transgene has integrated in a region accessible for 
transcriptional regulation and that using BAC transgenic mice is a valid approach to study the function of SOCS1 in the cell nucleus.

In order to show that Socs $1^{-/-} M G L^{\text {tg }}$ mice indeed lack SOCS1 in the cell nucleus, we tried staining of SOCS1 on lung sections by immunohistochemistry. However, we could not find a specific antibody that was not staining sections from Socs $1^{-/-}$mice. Therefore, we decided to apply a functional approach to verify non-nuclear expression of Socs1MGL. SOCS1 has been shown to induce proteasomal degradation of $\operatorname{NF\kappa B}(36,37)$ by interaction with p65 in the cell nucleus, thereby limiting induction of a subset of NFKB-dependent genes (38). Lack of nuclear SOCS1 leads to sustained activation of NFKB that could be confirmed using a transcription factor assay specifically for p65 (Figure S1 in Supplementary Material). Socs $1^{-/-} M G L^{\text {tg }}$ mice indeed showed sustained IL-12p40 protein levels in CD11 $\mathrm{c}^{+}$cells of the lung and spleen (Figure 2F). We did not detect differences regarding $\mathrm{TNF} \alpha$ protein levels (Figure S1 in Supplementary Material). Unlike TNF $\alpha$ that shows fast NFKB recruitment to a constitutively and immediately accessible promoter, $I L-12 p 40$ is a gene that needs prolonged binding of $\mathrm{NF \kappa B}$ to its promoter (44). Only a small subset of NFKB-dependent genes that is dependent on prolonged transcriptional activation is affected by sustained activation of p65 such as $I L-12 p 40$. Taken together, findings in $S_{0 c s} 1^{-/} M G L^{\text {tg }}$ mice are fully consistent with previously described in vitro data using non-nuclear SOCS $1 \Delta$ NLS (38), suggesting that Socs $1^{-/-} M G L^{\text {tg }}$ mice lack SOCS1 in the cell nucleus. In addition, we found a substantial number of differentially expressed genes annotated to TLR and TNF signaling, and NFKB-binding sites were overrepresented among those genes (Tables 1 and 2).

Socs $1^{-1-} M G L^{\text {tg }}$ mice, expressing only non-nuclear mutant Socs1 (Socs1 $1 \mathrm{NLS}$ ), survive the early lethal phenotype of Socs $1^{-/-}$mice (Figure 3; Figure S2 in Supplementary Material) that otherwise die within 3 weeks due to excessive immune signaling and multiorgan inflammation (24-26). The data show that SOCS1 1 NLS was sufficient to rescue lack of wild-type SOCS1. The disease in Socs1 knockout mice mainly depends on hyperresponsiveness to IFN $\gamma$ as it can be prevented in the neonatal period by the administration of anti-IFN $\gamma$ antibodies or by using Socs $1^{-/-} I F N \gamma^{-/-}$mice $(47,48)$. Therefore, we hypothesized that canonical IFN $\gamma$ signaling might still be efficiently regulated by Socs $1 \Delta N L S$. IFN $\gamma$ binds to the IFN $\gamma$ receptor complex, activates JAK1/2, and subsequently leads to tyrosine phosphorylation of STAT1 (pY-STAT1). pY-STAT1 dimers in turn translocate into the nucleus and activate transcription of "canonical" IFN $\gamma$-responsive genes $(15,16,58)$. Socs $1^{-/} M G L^{\text {tg }}$ mice showed functional regulation of canonical IFN $\gamma$ signaling, as shown by unaltered pY-STAT1 levels and whole-genome expression analysis in BMMs (Figures $\mathbf{5}$ and 6). In addition to canonical signaling, a number of studies have shown that pYSTAT1-independent pathways also exist (17-19). Besides their localization on the plasmamembrane, IFNAR1 and TYK2 have been shown to occur in the nucleus as well $(21,22)$. In addition, it has been shown that STATs translocate into the nucleus in a pY-independent manner, where they activate expression of only a subset of "non-canonical" IFN $\gamma$-induced genes (23). Indeed, a subset of non-canonical IFN $\gamma$ target genes were differentially regulated comparing BMMs of Socs $1^{-/-} M G L^{\text {tg }}$ and Socs $1^{+/-} M G L^{\text {tg }}$ mice. Pathway annotation did not reveal IFN $\gamma$ signaling to be differentially regulated, confirming that Socs $1 \Delta$ NLS was still able to regulate cytoplasmic signaling pathways and that canonical IFN $\gamma$ signaling was not altered in Socs $1^{-/-} M G L^{\text {tg }}$ mice. We observed minor, but non-significant differences in Icam-1 expression upon stimulation with IFN $\gamma$ comparing BMMs of Socs $1^{+/-} M G L^{\text {tg }}$ and Socs $1^{-/-} M G L^{\text {tg }}$ mice (Figure 5). This is in line with literature showing that upregulation of ICAM-1 by IFN $\gamma$ is inhibited by SOCS1 (59) with its inhibitory capacity depending on the functional NLS of SOCS1 (34).

We closely analyzed Socs $1^{-/-} M G L^{\text {tg }}$ mice for disease symptoms and found reduced body weight and spontaneous development of low-grade inflammation in the lung (Figure 7). Expression of SOCS1 in the lung has been reported for alveolar macrophages (60), bronchial epithelial cells (61), and eosinophils (62). Mice fully deficient for SOCS1 show extensive hematopoietic infiltration in the lung (26), arguing that SOCS1 is involved in immune regulation in the lung. Increased serum IgE levels in Socs $1^{-/} M G L^{\text {tg }}$ mice suggest an allergic airway disease. To analyze whether the Th2 bias observed in $\operatorname{Socs}^{-/-} M G L^{\text {tg }}$ mice is of physiological relevance, mice were challenged by either inhaled OVA or IL-13. Both, upon OVA sensitization and challenge as well as IL-13 instillation, Socs $1^{-/-} M G L^{\text {tg }}$ mice showed increased airway eosinophilia (Figure 8; Figure S4 in Supplementary Material). This is in line with previous data showing that serum IgE levels and infiltrating eosinophils were considerably increased in the lungs of OVA-treated Socs $1^{-/-} I F N \gamma^{-/-}$mice (63). So far, it is unclear how the lack of nuclear SOCS1 leads to airway eosinophilia. One hypothesis is that SOCS1 is crucial to maintain epithelial cell barrier function (Figure S5 in Supplementary Material). Sustained NFKB signaling might lead to an activation of the epithelium. We observed increased expression of the epithelial cell-derived cytokine $I L-33$ in primary murine trachea epithelial cells of Socs $1^{-/-} M G L^{\text {tg }}$ mice (Figure 9). Since it has been shown previously (64) that IL-33 has an impact on epithelial integrity, higher IL-33 levels in Socs $1^{-/-} M G L^{\text {tg }}$ mice might result in epithelial barrier disruption. Enhanced barrier permeability in turn might facilitate other immune cells such as DCs in initiate host defense mechanisms resulting in inflammation (65). Triggering of pattern recognition receptors on epithelial cells has been reported to release of IL-33 leading to an activation of DCs (66-68). Recently, it has been shown that IL-33 is constitutively expressed in the cell nucleus in epithelial cells (69) where direct interaction between SOCS1 and IL-33 might be possible. Furthermore, IL-13 has been shown to downregulate junctional components including E-cadherin in bronchiolar epithelial cells leading to disruptive effects on airway epithelial barrier function (70) and explaining why we see stronger eosinophilia upon IL-13 treatment. Indeed, higher SOCS1 expression has been shown to inhibit IL13 induced CCL26 expression in epithelial cells in vitro whereas reduced SOCS1 expression was correlated with enhanced airway eosinophilia (71). Epithelial cells of Socs $1^{-/-} M G L^{\text {tg }}$ mice produce more CCL26 which in turn attracts eosinophils resulting in airway eosinophilia (Figure S5 in Supplementary Material). 
The second hypothesis is that hematopoietic cells are the key players involved in nuclear SOCS1 induced airway eosinophilia. Lee et al. showed that serum IgE levels and infiltrating eosinophils were considerably increased in the lungs of OVA-treated Socs $1^{-/-} I F N \gamma^{-/-}$mice (63). They suggest that regulation of SOCS1 mainly affects hematopoietic cells, not epithelial cells. McCormick et al. showed that reduced expression of SOCS1 has been shown to prolong IL-4induced IRS-2 tyrosine phosphorylation and enhanced M2 differentiation (72). IRS-2 also plays a major role in allergic lung inflammation and remodeling (73). In addition, SOCS1 is important in helper $\mathrm{T}$ cell differentiation $(5,6,49)$ : it is rapidly induced in response to many cytokines, including IFN $\gamma$ and IL-4 and it is an important negative feedback inhibitor of both signaling pathways. When Socs $1^{-/-}$mice are crossed with either an $I F N \gamma^{-1-}$ or STAT6 ${ }^{-/-}$mice, survival is prolonged (47, $50)$, indicating that SOCS1 regulates both IFN $\gamma$-driven Th1 and IL-4-driven Th2 responses. Supporting this finding, CD4 ${ }^{+}$ $\mathrm{T}$ cells from Socs $1^{-/-}$mice spontaneously differentiate into Th1 and Th2 cells, thereby producing IFN $\gamma$ and IL-4, respectively $(31,50)$. It has previously been shown in vitro that SOCS1 is a negative regulator of Th2-dependent pathways, achieved by inhibition of pSTAT6 (74). In line with this, Socs $1^{-/-} M G L^{\text {tg }}$ mice showed enhanced percentage of $\mathrm{Gata}^{+} \mathrm{CD}^{+}$cells and increased expression of $I L-4, I L-5$, and $I L-13$, suggesting that nuclear SOCS1 plays a role in $\mathrm{T}$ cell differentiation. Even under neutral conditions, CD $4^{+} \mathrm{T}$ cells of Socs $1^{-1-} M G L^{\text {tg }}$ mice tend to differentiate into $\mathrm{Gata}^{+}$cells, arguing for a $\mathrm{T}$ cell intrinsic effect of nuclear SOCS1. Increased Th2 cytokines in Socs $1^{-/-} M G L^{\text {tg }}$ mice could in turn act on the epithelial cells. Further clarification will require generating bone marrow chimeras to differentiate between contributions of nuclear SOCS1 in cells sensitive for radiation (hematopoietic cells) or radiation-resistant cells (such as epithelial cells).

There have been several publications linking SOCS1 expression with allergic diseases such as asthma $(61,71,74,75)$. Gielen et al. (61) observed that nuclear SOCS1 suppressed rhinovirus induction of interferons, which is discussed to be associated with increased susceptibility to virus exacerbation in severe asthma. Since induction of interferons occurs via pattern recognition receptors that are linked to NFkB signaling, inhibition of NFkB signaling by nuclear SOCS1 might be a possible mechanism for the control of immunity in the lung. Socs 1 gene expression was significantly lower expressed in the airways of severe asthmatics compared with mild/moderate asthmatics, and was inversely associated with airway eosinophilia $(71,74)$, suggesting that the absence of SOCS1 leads to Th2 bias. Using Socs $1^{-1-} M G L^{\text {tg }}$ mice, we have shown for the first time, that not only the presence of SOCS1 but also the localization is crucial for effective regulation

\section{REFERENCES}

1. Alexander WS. Suppressors of cytokine signalling (SOCS) in the immune system. Nat Rev Immunol (2002) 2(6):410-6. doi:10.1038/nri818

2. Greenhalgh CJ, Hilton DJ. Negative regulation of cytokine signaling. J Leukoc Biol (2001) 70(3):348-56.

3. Yasukawa H, Misawa H, Sakamoto H, Masuhara M, Sasaki A, Wakioka T, et al. The JAK-binding protein JAB inhibits Janus tyrosine kinase activity through of Th2 responses. A study assessing functional variants of Socs 1 within a population of adult Japanese asthma patients found a significant association between the Socs 1 promoter polymorphism $(-1478 \mathrm{CA}<\mathrm{del})$ and adult asthma. It is suggested that promoter polymorphism leads to increased SOCS1 and inhibition of interferons, leading to higher susceptibility to virus-induced asthma exacerbations (75). Another study showed that expression of nuclear SOCS1 is increased in atopic asthmatic patients (61), which was associated with suppression of rhinovirus-induced interferons. The findings allow the conclusion that SOCS1 in the cell nucleus plays an important role in the regulation of local immunity in the lung that needs to be further investigated.

Taken together, Socs $1^{-/-} M G L^{\text {tg }}$ mice showed functional regulation of canonical IFN $\gamma$ signaling, but differential regulation of a subset of IFN $\gamma$-dependent genes, possibly due to alteration in NFאB signaling pathway. Socs $1^{-/-} M G L^{\text {tg }}$ mice spontaneously developed low-grade airway inflammation and had increased serum IgE levels and Th2 cytokines in the lung. Upon OVA sensitization and OVA aerosol challenge as well as IL-13 instillation, Socs $1^{-/} M G L^{\text {tg }}$ mice reacted with augmented influx of eosinophils, arguing for an immune regulatory function of nuclear SOCS1 in the lung. We present a valuable tool to study the nuclear function of SOCS1 in vivo that allows investigating local immune regulation in the lung by nuclear SOCS1.

\section{AUTHOR CONTRIBUTIONS}

$\mathrm{BA}, \mathrm{MWg}$, and $\mathrm{AD}$ designed the work and interpreted data. JZ, MWt, ST, FL, LL, ZO, and CV acquired and analyzed experimental data. BA, GK, PW, and AD generated the BAC transgenic mouse. $\mathrm{SB}$ analyzed and interpreted data. JZ, MWg, MWt, and AD wrote the manuscript.

\section{ACKNOWLEDGMENTS}

This work was supported by grants of the Deutsche Forschungsgemeinschaft to AD (Da592/4-2, Da592/6-1, SFB938/E). We thank the microarray unit of the Genomics and Proteomics Core Facility [German Cancer Research Center (DKFZ)] for providing the Illumina Whole-Genome Expression Beadchips and related services. We also thank Suzan Leccese, René Karayilan, Juliane Artelt, Franziska Beyersdorf, Frauke Koops, and Linda Lang for excellent technical assistance.

\section{SUPPLEMENTARY MATERIAL}

The Supplementary Material for this article can be found online at http://journal.frontiersin.org/article/10.3389/fimmu. 2016.00514/full\#supplementary-material.

binding in the activation loop. EMBO J (1999) 18(5):1309-20. doi:10.1093/ emboj/18.5.1309

4. Endo TA, Masuhara M, Yokouchi M, Suzuki R, Sakamoto H, Mitsui K, et al. A new protein containing an SH2 domain that inhibits JAK kinases. Nature (1997) 387(6636):921-4. doi:10.1038/43213

5. Naka T, Narazaki M, Hirata M, Matsumoto T, Minamoto S, Aono A, et al. Structure and function of a new STAT-induced STAT inhibitor. Nature (1997) 387(6636):924-9. doi:10.1038/43219 
6. Starr R, Willson TA, Viney EM, Murray LJ, Rayner JR, Jenkins BJ, et al. A family of cytokine-inducible inhibitors of signalling. Nature (1997) 387(6636):917-21. doi:10.1038/43206

7. Fenner JE, Starr R, Cornish AL, Zhang J-G, Metcalf D, Schreiber RD, et al. Suppressor of cytokine signaling 1 regulates the immune response to infection by a unique inhibition of type I interferon activity. Nat Immunol (2006) 7(1):33-9. doi:10.1038/ni1287

8. Qing Y. Role of tyrosine 441 of interferon-receptor subunit 1 in SOCS-1mediated attenuation of STAT1 activation. J Biol Chem (2004) 280(3):1849-53. doi:10.1074/jbc.M409863200

9. Vuong BQ, Arenzana TL, Showalter BM, Losman J, Chen XP, Mostecki J, et al. SOCS-1 localizes to the microtubule proteasome SOCS-1 localizes to the microtubule organizing complex-associated 20S proteasome. Mol Cell Biol (2004) 24(20):9092-101. doi:10.1128/MCB.24.20.9092

10. Zhang JG, Farley A, Nicholson SE, Willson TA, Zugaro LM, Simpson RJ, et al. The conserved SOCS box motif in suppressors of cytokine signaling binds to elongins $\mathrm{B}$ and $\mathrm{C}$ and may couple bound proteins to proteasomal degradation. Proc Natl Acad Sci U S A (1999) 96(5):2071-6. doi:10.1073/pnas.96.5.2071

11. Kinjyo I, Hanada T, Inagaki-Ohara K, Mori H, Aki D, Ohishi M, et al. SOCS1/ $\mathrm{JAB}$ is a negative regulator of LPS-induced macrophage activation. Immunity (2002) 17(5):583-91. doi:10.1016/S1074-7613(02)00446-6

12. Nakagawa R, Naka T, Tsutsui H, Fujimoto M, Kimura A, Abe T, et al. SOCS-1 participates in negative regulation of LPS responses. Immunity (2002) 17(5):677-87. doi:10.1016/S1074-7613(02)00449-1

13. Baetz A, Frey M, Heeg K, Dalpke AH. Suppressor of cytokine signaling (SOCS) proteins indirectly regulate toll-like receptor signaling in innate immune cells. J Biol Chem (2004) 279(52):54708-15. doi:10.1074/jbc.M410992200

14. Mansell A, Smith R, Doyle SL, Gray P, Fenner JE, Crack PJ, et al. Suppressor of cytokine signaling 1 negatively regulates toll-like receptor signaling by mediating Mal degradation. Nat Immunol (2006) 7(2):148-55. doi:10.1038/ni1299

15. Rutherford MN, Kumar A, Coulombe B, Skup D, Carver DH, Williams BR. Expression of intracellular interferon constitutively activates ISGF3 and confers resistance to EMC viral infection. J Interferon Cytokine Res (1996) 16:507-10. doi:10.1089/jir.1996.16.507

16. Stark GR, Kerr IM, Williams BR, Silverman RH, Schreiber RD. How cells respond to interferons. Annu Rev Biochem (1998) 67:227-64. doi:10.1146/ annurev.biochem.67.1.227

17. Gil MP, Bohn E, O'Guin AK, Ramana CV, Levine B, Stark GR, et al. Biologic consequences of Stat1-independent IFN signaling. Proc Natl Acad Sci U S A (2001) 98(12):6680-5. doi:10.1073/pnas.111163898

18. Ramana CV, Gil MP, Han Y, Ransohoff RM, Schreiber RD, Stark GR. Stat1independent regulation of gene expression in response to IFN- $\gamma$. Proc Natl Acad Sci U S A (2001) 98(12):6674-9. doi:10.1073/pnas.111164198

19. Soler C, Felipe A, García-Manteiga J, Serra M, Guillén-Gómez E, Casado FJ, et al. Interferon-gamma regulates nucleoside transport systems in macrophages through signal transduction and activator of transduction factor 1 (STAT1)-dependent and -independent signalling pathways. Biochem J (2003) 375(Pt 3):777-83. doi:10.1042/BJ20030260

20. Joshi S, Kaur S, Kroczynska B, Platanias LC. Mechanisms of mRNA translation of interferon stimulated genes. Cytokine (2010) 52(1-2):123-7. doi:10.1016/j. cyto.2010.03.019

21. Ahmed CM, Noon-Song EN, Kemppainen K, Pascalli MP, Johnson HM. Type I IFN receptor controls activated TYK2 in the nucleus: implications for EAE therapy. JNeuroimmunol (2013) 254(1-2):101-9. doi:10.1016/j. jneuroim.2012.10.006

22. Larkin J, Johnson HM, Subramaniam PS. Differential nuclear localization of the IFNGR-1 and IFNGR-2 subunits of the IFN-gamma receptor complex following activation by IFN-gamma. J Interferon Cytokine Res (2000) 20(6):565-76. doi:10.1089/10799900050044769

23. Cheon H, Stark GR. Unphosphorylated STAT1 prolongs the expression of interferon-induced immune regulatory genes. Proc Natl Acad Sci U S A (2009) 106(23):9373-8. doi:10.1073/pnas.0903487106

24. Marine JC, Topham DJ, McKay C, Wang D, Parganas E, Stravopodis D, et al. SOCS1 deficiency causes a lymphocyte-dependent perinatal lethality. Cell (1999) 98(5):609-16. doi:10.1016/S0092-8674(00)80048-3

25. Naka T, Matsumoto T, Narazaki M, Fujimoto M, Morita Y, Ohsawa Y, et al. Accelerated apoptosis of lymphocytes by augmented induction of Bax in SSI-1 (STAT-induced STAT inhibitor-1) deficient mice. Proc Natl Acad Sci U S A (1998) 95(26):15577-82. doi:10.1073/pnas.95.26.15577
26. Starr R, Metcalf D, Elefanty AG, Brysha M, Willson TA, Nicola NA, et al. Liver degeneration and lymphoid deficiencies in mice lacking suppressor of cytokine signaling-1. Proc Natl Acad Sci U S A (1998) 95(24):14395-9. doi:10.1073/ pnas.95.24.14395

27. Zhang JG, Metcalf D, Rakar S, Asimakis M, Greenhalgh CJ, Willson TA, et al. The SOCS box of suppressor of cytokine signaling- 1 is important for inhibition of cytokine action in vivo. Proc Natl Acad Sci U S A (2001) 98(23):13261-5. doi:10.1073/pnas.231486498

28. Metcalf D, Mifsud S, Di Rago L, Nicola NA, Hilton DJ, Alexander WS. Polycystic kidneys and chronic inflammatory lesions are the delayed consequences of loss of the suppressor of cytokine signaling-1 (SOCS-1). Proc Natl Acad Sci U S A (2002) 99(2):943-8. doi:10.1073/pnas.022628499

29. Eyles JL, Metcalf D, Grusby MJ, Hilton DJ, Starr R. Negative regulation of interleukin-12 signaling by suppressor of cytokine signaling-1. J Biol Chem (2002) 277(46):43735-40. doi:10.1074/jbc.M208586200

30. Tanaka K, Ichiyama K, Hashimoto M, Yoshida H, Takimoto T, Takaesu G, et al. Loss of suppressor of cytokine signaling 1 in helper $\mathrm{T}$ cells leads to defective Th17 differentiation by enhancing antagonistic effects of IFNgamma on STAT3 and Smads. J Immunol (2008) 180(6):3746-56. doi:10.4049/ jimmunol.180.6.3746

31. Fujimoto M, Tsutsui H, Yumikura-Futatsugi S, Ueda H, Xingshou O, Abe T, et al. A regulatory role for suppressor of cytokine signaling-1 in $\mathrm{T}(\mathrm{h})$ polarization in vivo. Int Immunol (2002) 14(11):1343-50. doi:10.1093/intimm/ dxf094

32. Trop S, De Sepulveda P, Zuniga-Pflucker JC, Rottapel R. Overexpression of suppressor of cytokine signaling-1 impairs pre-T-cell receptor-induced proliferation but not differentiation of immature thymocytes. Blood (2001) 97:2269-77. doi:10.1182/blood.V97.8.2269

33. Baetz A, Koelsche C, Strebovsky J, Heeg K, Dalpke AH. Identification of a nuclear localization signal in suppressor of cytokine signaling 1. FASEB $J$ (2008) 22(12):4296-305. doi:10.1096/f.08-116079

34. Koelsche C, Strebovsky J, Baetz A, Dalpke AH. Structural and functional analysis of a nuclear localization signal in SOCS1. Mol Immunol (2009) 46(13):2474-80. doi:10.1016/j.molimm.2009.05.020

35. Mallette FA, Calabrese V, Ilangumaran S, Ferbeyre G. SOCS1, a novel interaction partner of p53 controlling oncogene-induced senescence. Aging (2010) 2(7):445-52. doi:10.18632/aging.100163

36. Maine GN, Mao X, Komarck CM, Burstein E. COMMD1 promotes the ubiquitination of NF-kB subunits through a Cullin-containing ubiquitin ligase. EMBO J (2007) 26(2):436-47. doi:10.1038/sj.emboj.7601489

37. Ryo A, Suizu F, Yoshida Y, Perrem K, Liou YC, Wulf G, et al. Regulation of NF-. Mol Cell (2003) 12(6):1413-26. doi:10.1016/S1097-2765(03)00490-8

38. Strebovsky J, Walker P, Lang R, Dalpke AH. Suppressor of cytokine signaling 1 (SOCS1) limits NFkappaB signaling by decreasing p65 stability within the cell nucleus. FASEB J (2011) 25(3):863-74. doi:10.1096/fj.10170597

39. Eberle ME, Dalpke AH. Dectin-1 stimulation induces suppressor of cytokine signaling 1, thereby modulating TLR signaling and T cell responses. J Immunol (2012) 188(11):5644-54. doi:10.4049/jimmunol.1103068

40. Eberwine J, Yeh H, Miyashiro K, Cao Y, Nair S, Finnell R, et al. Analysis of gene expression in single live neurons. Proc Natl Acad Sci U S A (1992) 89(7):3010-4. doi:10.1073/pnas.89.7.3010

41. Lunding LP, Webering S, Vock C, Wagner C, Hölscher C, Wegmann M. Poly(inosinic-cytidylic) acid - triggered exacerbation of experimental asthma depends on IL-17A produced by NK cells. J Immunol (2015) 194(12):5615-25. doi:10.4049/jimmunol.1402529

42. Neuhaus-Steinmetz U, Glaab T, Daser A, Braun A, Lommatzsch M, Herz U, et al. Sequential development of airway hyperresponsiveness and acute airway obstruction in a mouse model of allergic inflammation. Int Arch Allergy Immunol (2000) 121(1):57-67. doi:10.1159/000024298

43. Davidson DJ, Kilanowski FM, Randall SH, Sheppard DN, Dorin JR. A primary culture model of differentiated murine tracheal epithelium. Am J Physiol Lung Cell Mol Physiol (2000) 279(4):L766-78.

44. Bode KA, Schmitz F, Vargas L, Heeg K, Dalpke AH. Kinetic of RelA activation controls magnitude of TLR-mediated IL-12p40 induction. J Immunol (2009) 182(4):2176-84. doi:10.4049/jimmunol.0802560

45. Chau V, Tobias JW, Bachmair A, Marriotr D, Ecker DJ, Gonda DK, et al. A multiubiquitin chain is confined to specific lysine in a targeted shortlived protein. Science (1989) 243(1982):1576-83. doi:10.1126/science.2538923 
46. Glickman MH, Ciechanover A. The ubiquitin-proteasome proteolytic pathway: destruction for the sake of construction. Physiol Rev (2002) 82(2):373-428. doi:10.1152/physrev.00027.2001

47. Alexander WS, Starr R, Fenner JE, Scott CL, Handman E, Sprigg NS, et al. SOCS1 is a critical inhibitor of interferon $\gamma$ signaling and prevents the potentially fatal neonatal actions of this cytokine. Cell (1999) 98:597-608. doi:10.1016/S0092-8674(00)80047-1

48. Bullen DV, Darwiche R, Metcalf D, Handman E, Alexander WS. Neutralization of interferon-gamma in neonatal SOCS1-/- mice prevents fatty degeneration of the liver but not subsequent fatal inflammatory disease. Immunology (2001) 104(1):92-8. doi:10.1046/j.1365-2567.2001.01294.x

49. Dickensheets H, Vazquez N, Sheikh F, Gingras S, Murray PJ, Ryan JJ, et al. Suppressor of cytokine signaling-1 is an IL-4-inducible gene in macrophages and feedback inhibits IL-4 signaling. Genes Immun (2007) 8(1):21-7. doi:10.1038/sj.gene.6364352

50. Naka T, Tsutsui H, Fujimoto M, Kawazoe Y, Kohzaki H, Morita Y, et al. SOCS-1/SSI-1-deficient NKT cells participate in severe hepatitis through dysregulated cross-talk inhibition of IFN-gamma and IL-4 signaling in vivo. Immunity (2001) 14(5):535-45. doi:10.1016/S1074-7613(01)00132-7

51. Sel S, Wegmann M, Dicke T, Sel S, Henke W, Yildirim AO, et al. Effective prevention and therapy of experimental allergic asthma using a GATA3-specific DNAzyme. JAllergy Clin Immunol (2008) 121(4):910.e-6.e. doi:10.1016/j.jaci.2007.12.1175

52. Provost V, Larose M-C, Langlois A, Rola-Pleszczynski M, Flamand N, Laviolette M. CCL26/eotaxin-3 is more effective to induce the migration of eosinophils of asthmatics than CCL11/eotaxin-1 and CCL24/eotaxin-2. J Leukoc Biol (2013) 94(2):213-22. doi:10.1189/jlb.0212074

53. Cubells JF, Schroeder JP, Barrie ES, Manvich DF, Sadee W, Berg T, et al. Human bacterial artificial chromosome (BAC) transgenesis fully rescues noradrenergic function in dopamine $\beta$-hydroxylase knockout mice. PLoS One (2016) 11(5):e0154864. doi:10.1371/journal.pone.0154864

54. Huang M, Zhang W, Guo J, Wei X, Phiwpan K, Zhang J, et al. Improved transgenic mouse model for studying HLA class I antigen presentation. Sci Rep (2016) 6:33612. doi:10.1038/srep33612

55. Song K, Wang H, Kamm GB, Pohle J, Reis FDC, Heppenstall P, et al. The TRPM2 channel is a hypothalamic heat sensor that limits fever and can drive hypothermia. Science (2016) 353(6306):1393-8. doi:10.1126/science.aaf7537

56. Walker WH, Easton E, Moreci RS, Toocheck C, Anamthathmakula P, Jeyasuria P. Restoration of spermatogenesis and male fertility using an androgen receptor transgene. PLoS One (2015) 10(3):e0120783. doi:10.1371/journal. pone. 0120783

57. Siewert E, Müller-Esterl W, Starr R, Heinrich PC, Schaper F. Different protein turnover of interleukin-6-type cytokine signalling components. Eur J Biochem (1999) 265(1):251-7. doi:10.1046/j.1432-1327.1999.00719.x

58. Ahmed CM, Wills KN, Sugarman BJ, Johnson DE, Ramachandra M, Nagabhushan TL, et al. Selective expression of nonsecreted interferon by an adenoviral vector confers antiproliferative and antiviral properties and causes reduction of tumor growth in nude mice. J Interferon Cytokine Res (2001) 21(6):399-408. doi:10.1089/107999001750277871

59. Park ES, Kim H, Suh JM, Park SJ, Kwon OY, Kim YK, et al. Thyrotropin induces SOCS-1 (suppressor of cytokine signaling-1) and SOCS-3 in FRTL-5 thyroid cells. Mol Endocrinol (2000) 14(3):440-8. doi:10.1210/me.14.3.440

60. Dong R, Xie L, Zhao K, Zhang Q, Zhou M, He P. Cigarette smoke-induced lung inflammation in COPD mediated via LTB4/BLT1/SOCS1 pathway. Int J Chron Obstruct Pulmon Dis (2016) 11:31-41. doi:10.2147/COPD.S96412

61. Gielen V, Sykes A, Zhu J, Chan B, Macintyre J, Regamey N, et al. Increased nuclear suppressor of cytokine signaling 1 in asthmatic bronchial epithelium suppresses rhinovirus induction of innate interferons. J Allergy Clin Immunol (2015) 136(1):177.e-88.e. doi:10.1016/j.jaci.2014.11.039

62. Burnham ME, Koziol-White CJ, Esnault S, Bates ME, Evans MD, Bertics PJ, et al. Human airway eosinophils exhibit preferential reduction in STAT signaling capacity and increased CISH expression. J Immunol (2013) 191(6):2900-6. doi:10.4049/jimmunol.1300297
63. Lee C, Kolesnik TB, Caminschi I, Chakravorty A, Carter W, Alexander WS, et al. Suppressor of cytokine signalling 1 (SOCS1) is a physiological regulator of the asthma response. Clin Exp Allergy (2009) 39(6):897-907. doi:10.1111/j.1365-2222.2009.03217.x

64. Heyen L, Müller U, Siegemund S, Schulze B, Protschka M, Alber G, et al. Lung epithelium is the major source of IL-33 and is regulated by IL-33dependent and IL-33-independent mechanisms in pulmonary cryptococcosis. Pathog Dis (2016) 74(7):ftw086. doi:10.1093/femspd/ftw086

65. Hammad H, Lambrecht BN. Dendritic cells and epithelial cells: linking innate and adaptive immunity in asthma. Nat Rev Immunol (2008) 8(3):193-204. doi:10.1038/nri2275

66. Hammad H, Chieppa M, Perros F, Willart MA, Germain RN, Lambrecht $\mathrm{BN}$. House dust mite allergen induces asthma via TLR4 triggering of airway structural cells. Nat Med (2009) 15(4):410-6. doi:10.1038/nm.1946

67. Kool M, Willart MA, van Nimwegen M, Bergen I, Pouliot P, Virchow JC, et al. An unexpected role for uric acid as an inducer of $\mathrm{T}$ helper 2 cell immunity to inhaled antigens and inflammatory mediator of allergic asthma. Immunity (2011) 34(4):527-40. doi:10.1016/j.immuni.2011.03.015

68. Phipps S, Chuan EL, Kaiko GE, Shen YF, Collison A, Mattes J, et al. Toll/IL-1 signaling is critical for house dust mite-specific Th1 and Th2 responses. Am J Respir Crit Care Med (2009) 179(10):883-93. doi:10.1164/ rccm.200806-974OC

69. Moussion C, Ortega N, Girard JP. The IL-1-like cytokine IL-33 is constitutively expressed in the nucleus of endothelial cells and epithelial cells in vivo: a novel "alarmin"? PLoS One (2008) 3(10):e3331. doi:10.1371/journal.pone. 0003331

70. Saatian B, Rezaee F, Desando S, Emo J, Chapman T, Knowlden S, et al. Interleukin-4 and interleukin-13 cause barrier dysfunction in human airway epithelial cells TL - 1. Tissue Barriers (2013) 1(2):e24333. doi:10.4161/ tisb. 24333

71. Doran E, Choy DF, Shikotra A, Butler CA, O'Rourke DM, Johnston JA, et al. Reduced epithelial suppressor of cytokine signalling 1 in severe eosinophilic asthma. Eur Respir J (2016) 48(3):715-25. doi:10.1183/13993003. 00400-2015

72. McCormick SM, Gowda N, Fang JX, Heller NM. Suppressor of cytokine signaling (SOCS) 1 regulates IL-4-activated insulin receptor substrate (IRS)-2 tyrosine phosphorylation in monocytes and macrophages via the proteasome. J Biol Chem (2016) 291(39):20574-87. doi:10.1074/jbc.M116.746164

73. Dasgupta P, Dorsey N, Li J, Qi X, Smith E, Yamaji-Kegan K, et al. The adaptor protein insulin receptor substrate 2 inhibits alternative macrophage activation and allergic lung inflammation. Science (2016) 9(433):ra63. doi:10.1126/ scisignal.aad6724

74. Fukuyama S, Nakano T, Matsumoto T, Oliver BGG, Burgess JK, Moriwaki A, et al. Pulmonary suppressor of cytokine signaling-1 induced by IL-13 regulates allergic asthma phenotype. Am J Respir Crit Care Med (2009) 179(11):992-8. doi:10.1164/rccm.200806-992OC

75. Harada M, Nakashima K, Hirota T, Shimizu M, Doi S, Fujita K, et al. Functional polymorphism in the suppressor of cytokine signaling 1 gene associated with adult asthma. Am J Respir Cell Mol Biol (2007) 36(4):491-6. doi:10.1165/ rcmb.2006-0090OC

Conflict of Interest Statement: The authors declare that the research was conducted in the absence of any commercial or financial relationships that could be construed as a potential conflict of interest.

Copyright $\odot 2016$ Zimmer, Weitnauer, Boutin, Küblbeck, Thiele, Walker, Lasitschka, Lunding, Orinska, Vock, Arnold, Wegmann and Dalpke. This is an open-access article distributed under the terms of the Creative Commons Attribution License (CC BY). The use, distribution or reproduction in other forums is permitted, provided the original author(s) or licensor are credited and that the original publication in this journal is cited, in accordance with accepted academic practice. No use, distribution or reproduction is permitted which does not comply with these terms. 